28.

\title{
Ariminalpolitif由e Aufgubrn.
}

Bon \$rofefior v. Lişzt in Marburg.

ชortiefung.

(खgl. oben @eite 498.)

\section{Die furzzeitige Freibeitoftrafe.}

ßollen wir bas Strafenifyitem eimes Ranbes fenten lernen, fo

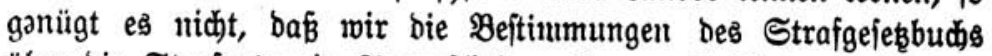
über bie Strafarten in Angenjo)eill negment. Entjdeidend für bas Ergebnis ber Unteriuchung ift nur bie thatiäd)lid)e $\mathfrak{A}$ nwelloung ber im Bejeßze vorgejehenen Strafmittel. über bie \$andhabung bes

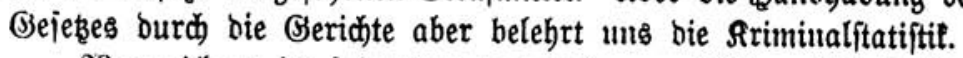

Wemm id) es im folgenbent unternebme, geittigt auf bie Zablen=

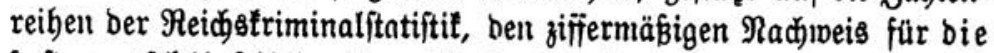
faît ausidlieblide Gerridaft ber turzzeitigen Freibeits= ftraje in ber beutident Strafredtopflege zu erbringen, fo faum es fidi für midy nur um bie möglidjite Berbreitung einer feft:

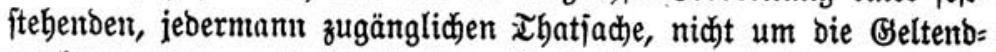
mad)ung neuer uno jelbftänbiger Beobad)tungen bantoln. Ditrfte bic Renutnis ber einfachiten triminaliftatijtijden Thatjachen, wie man es wobl zul erwarten berechtigt wäre, in Fadftreijen porausgejeşt werben, fo fönnte id) mir und meinen sejern bie folgenben 2 uss= fiibrungen iparen. Maut mirb es mir aber faum verübeln fönnen, menn id) meine befdjeibenten 3 meifel bege.

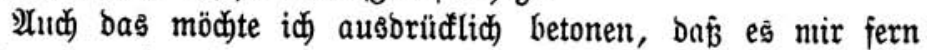
liegt, gegen irgello jemanten, jei es den Jejęgeber, jei es ben 


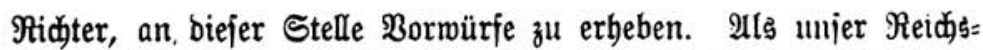
ftrajgejesbuch) entmorfen und beraten muroe, ba ging bas allgemeine, von ben Etimmfübrern ber \$3iffenfdaft getragene \$ierlangen nad

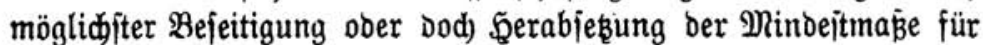
Strajarten und Strajrahmen, nad) möglidjiter Ermeiterung Des Spielraums für bns freie rid̄terlidje Ërmē̄en. Der Öejebgeber iit bem 3uge ber Zeit gejolgt, als er jeine weiten, nad) unten zu meijt

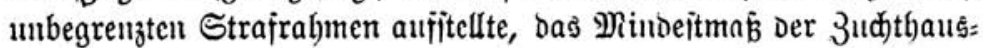

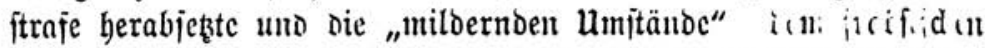

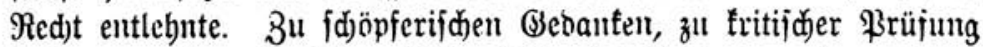
hatte man bamals teine 3eit. Dic vicl beflagte und getabelte Milde unirer Strafricter aber, ihre Sd)ell, über bas Mintoftmás

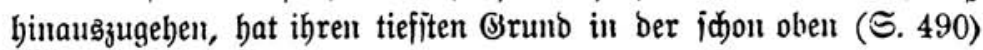
betonten Thatjad)e, baf̧ bie Âfgabe der Strafzuneïıug, mie bie "vergeltento" (Bstredtigfeit jie jtellt, einte unlöslide ijt und bleiben muis. Es mag aud), wie $\mathscr{A} j$ d) rott Z IX 10 betont, bie über= zeugung von ber gänzliden Wirfungslofigfeit unirer tojtjpieligen Joreiheitsjitrajen uid)t ganz ohne Einflub auf bie Entideibutgen Der Strafgcridjtc gebliebent jein. ')

¿ajien mir aljo bic 3iffern ipred)en. Dem V. Wanbe ber Reidjsfriminalitatijtif entmehme idy bie nadjitebentbe Tabclle.

1) Dennod fann id) çె mir nidjt veríagen, an snci cbenfoichr befanntc mic

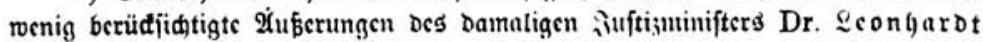

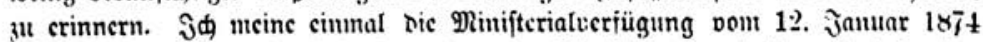
(3ujtizminijterialblatt S. 31), in meldaer Der Minifter Darauf ljinrecift, Daf nid)t

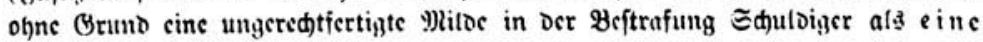
ber gan; cen bürgerliden (Scfsllfd)aft brobenoc (Scfabr emepiunden weroc,

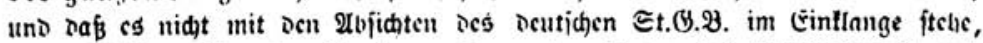
wenn bei Tlusmejijung Der Gtrufe von Der untern (Yrenje bes Strafrahmens aus: gegangen und bicic nur ba überịd)ritten werbc, two beftimute Straferböbungs: gründe vorlicgen. Und meiter crinnere id) an Dic Worte bes פiunifterŝ in Der

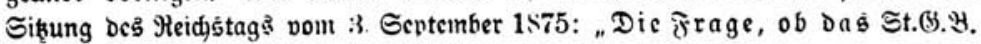

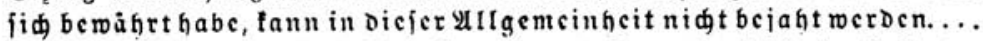

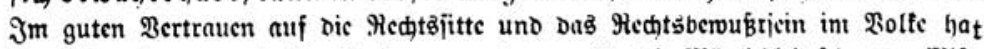

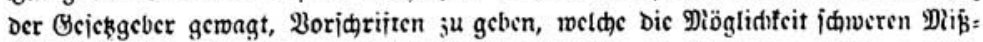

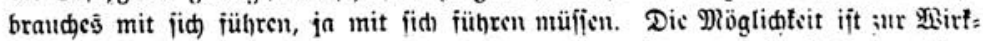

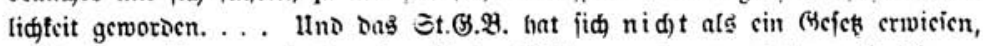
weld̈es gegenüber $n e n$ in oen betrefïenoen Miditungen hervorgetretenen itruibaren ober bod) jtraịmürbigen .jounblungen Dic criorocrlide Mepreifion gemährt." 


\section{Tabelle VII.}

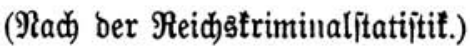

Berbältuismmäßige Şäu户̈gfeit ber $\mathfrak{A n m e n t u n g ~ b c r ~ v e r ~}$ idiedenen Strafarten.

\begin{tabular}{|c|c|c|c|c|c|}
\hline $\begin{array}{l}\text { Bon je } 100 \text { ïberha } \\
\text { wurben ver }\end{array}$ & 1882 & 1883 & 1884 & 1885 & 1886 \\
\hline 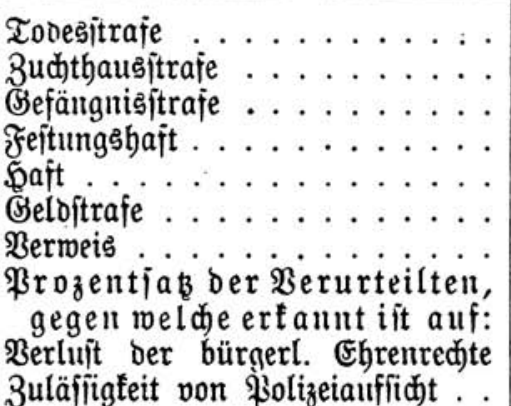 & \begin{tabular}{|r}
0,03 \\
4,17 \\
69,13 \\
0,03 \\
0,44 \\
25,33 \\
0,97
\end{tabular} & $\begin{array}{r}0,03 \\
3,74 \\
68,00 \\
0,05 \\
0,44 \\
26,70 \\
1,04\end{array}$ & \begin{tabular}{|r}
0,02 \\
$3,4 k$ \\
$66, \times 9$ \\
0,05 \\
0,42 \\
28,10 \\
1,04
\end{tabular} & $\begin{array}{r}0,02 \\
3,36 \\
65,72 \\
0,05 \\
0,37 \\
2 !, 136 \\
1,12\end{array}$ & $\begin{array}{r}0,02 \\
3,22 \\
64,05 \\
0,02 \\
0,37 \\
30,7 \% \\
1,14\end{array}$ \\
\hline
\end{tabular}

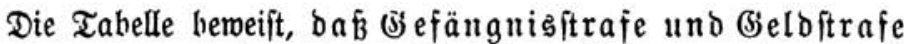
zufammen etma $95 \%$ aller Strajurteile ausmad)en, baß auf alle übrigen Strajarten zujammen uur ctma $5 \%$, alf 3udthaus allein zwijden 3 un $4 \%$, anf (s)ejängniştraje alleill bagegen zwijden 64 und $70 \%$ entiallen. Beadjtens= mert wäre nođ), baf́ von 1882 bie 1886 bic $\mathscr{U}$ mentung von 3udthaus und Sefängnisftrafe in unuterbrodencm Sinfell, die ber belditrafe jomie bes Eerweifes dagegen in ebenjo ununterbrodenem Steigen begriffu iit. Utud Die 2Aberfenumg oer bürgerlidjen (Ehrenred)te uno bie Zullaffung von Polizeiuufifidst ift von Эabr zu Jabr jeltener geworben.

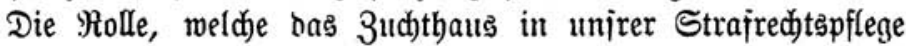
ipielt, ift mithin eine gänzlid) untergeorbnete. Э̧d) merbe aus biejen

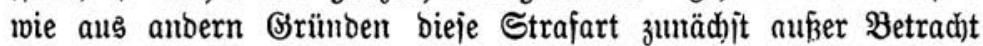

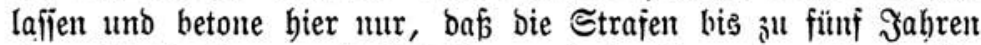
etma $87 \%$, bie von jünf J̧ahren uno Darüber ctwa $13 \%$ aller

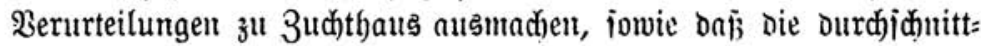
lide Dauer bes 3udhthaujes etwas über żwei und ein balbes ìabr beträgt. 


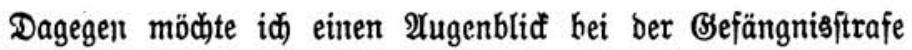

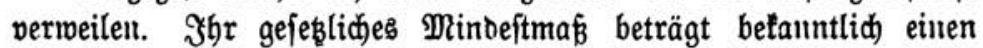

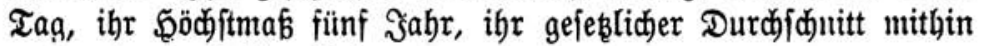
zmei unb eit halbes Эahr.

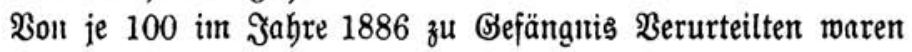
aber verurteilt nach)

\section{Tabelle VIII.}

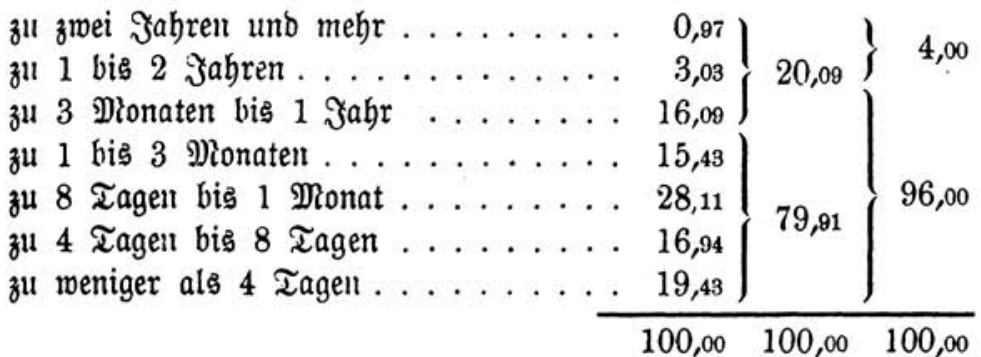

Die Zahlen ber Sorjabre zeigen feine wejentlidbe 2(bmeid)ung. Unter 100 zu Befängnis Berurteilten merben aljo etra $80 \%$ ober vier F̈̈̈nftel zul einer Frreiheitştrafe unter 3 Nonaten, etra $20 \%$ ober ein Füuftel zul einer Freibeitsftrafe von brei Monaten unb mebr verurteilt. Dabei beadjte man, bá̉ alle gerabe auf brei Monate, nidft mehr und nidht meniger, lautenden Ertenntniffe in jenen $20 \%$ bereits mitgezäblt fiutb. Es bleibt ferner die Z3ahl berjenigent F̧älle, in welch)en auf Befäınnis von brei Monaten uno bariiber crfanut murbe, mur mentig zurïd hinter Der 3 ahl ber

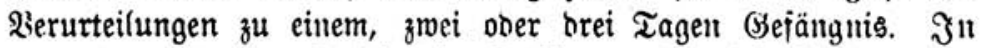
etwa bem fünften Teil aller Fälle erreid)t bie Befängnis: ftrafe nidt einmal bie Dauter von vier Tagen; in mebr als einem Drittel aller Fälle nid)t bie Daller voul adt Tagen. Rur in vier Fällen von hunbert wurbe auf $\mathfrak{B} e=$ fängnis von einem Jahr unb barüber, in 96 Fällen ba= gegen auf SSefängnis unter einem Jahre erfannt. Fes tanm uns bemnad) and) nidyt munber nebmen, wenn bie thatiäd)lidje

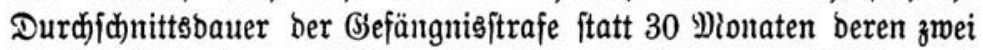

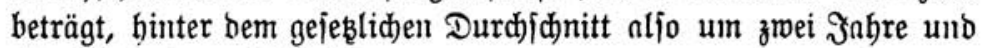
vier Nonate zurüđGleibt.

Die folgende überfid)t zeigt uns bie Strenge Der Serid)te in ber $\mathfrak{A}$ umendung ber Ģejängnisjtrafe auj einzelne Delitte. 
Tabelle IX. (Siebe Bemertung zu Tabelle I, S. 477.)

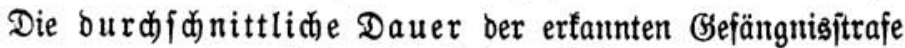
betrug im Эabre 1886:

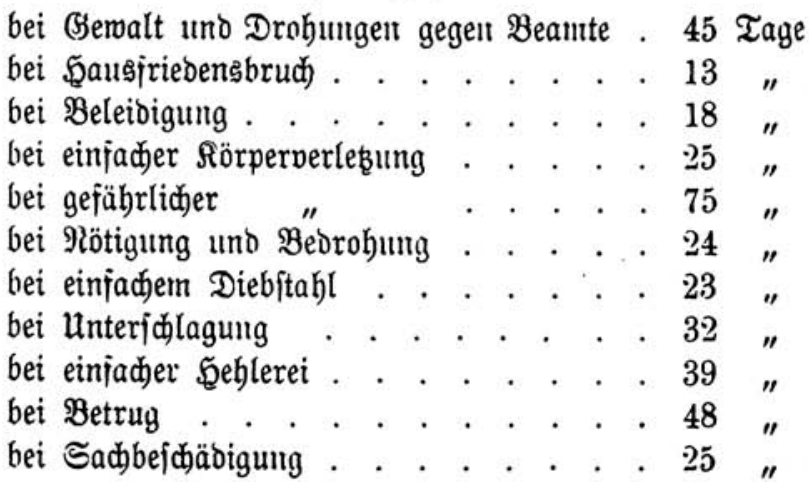

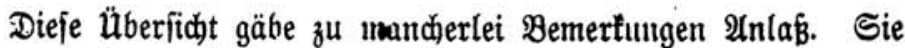

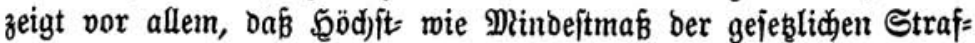
brohungen von jehr untergeorbnetem Einfluk auf bie thatjärdidid erfannte Straje ift. So beträgt das Đödjtmaß̄ ber gegen Sad)= bejdäbigung alt zmeiter Stelle neben Seloftraje angebrohten Be=

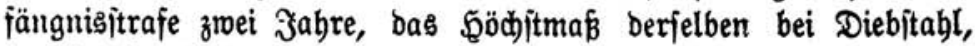
mo fie als einzige Strafe verbängt wiro, fünf Эałre; ber thatjäd)= lidje Durdjidnitt Dagegen ijt bort um zmei Tage höher als bier. Bei ber Unteridlagung, weldhe nad Den geję̧lidien Straforobungen Dem Diebitabl gegenuber als bas mildere Delitt erjheint, ift bie thatjäd)lid) erfaunte frreiheitêftrafe weientlid bärter als bei biejem. Der Betrug wird mebr als Doppelt fo ftreng geftraft wie ber Dieb=

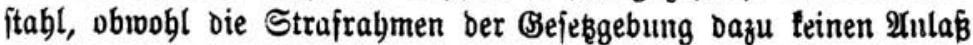

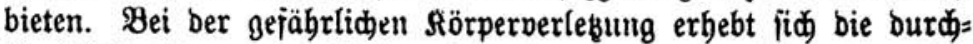

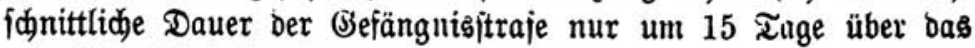
gejeşlidje Mitubejtmaß̄.

Sehen wir nod) etwas näber z̆l. Der einjacje Diebjtahl wiro nach St.S..B. \$ 242 mit Bejängnis -von einem Tage bis zu fünf

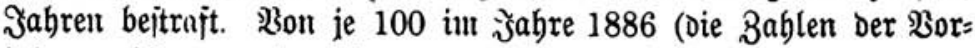
jabre weichen wenig ab) wegen einjachen Diebitabls ß̉erurteilten famen fajt 4 mit bem Bermeis, mehr als ein Drittel $(35,62)$ mit BSefängnis von einem, zwei ober brei Tagen bavon; fajt $90 \mathrm{er}=$ bielten Bsefänguis von weniger als brei Dionaten, uid)t ganz 6

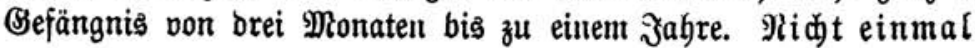


ein ganzes \$rozent ber jämtliden Berurteilten wurbe mit (j) füngnis von einem Jahre uno Darüber bejtraft. Der Etrafrabmen für einfad)en Diebjtahl ift mithin von unjrer

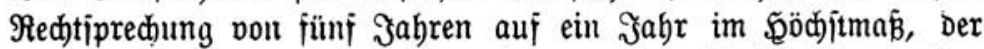

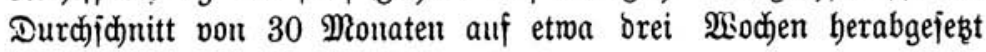
morben!

Diejelbe Erjaheinung wieverholt fich bei allen übrigen 2 er=

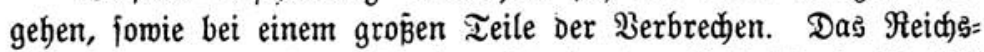

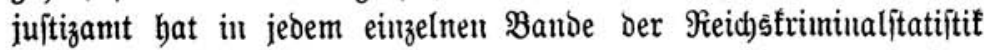
auf jie hingemieien: obne jeben Erjolg. Die Etrajrabmen unjres

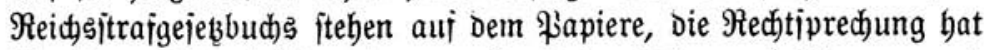
für ibren B̈edari fich anore zuredtgelegt. Die nad) Tagen und \$oden bereduete Freibeitsitrafe beherridt unje ge= famte Strafredistopleg̣e.

Und man beadte es mohl: Unjre Zahlen beruben aujidjlieslid

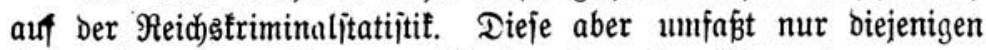
Berurteilungen, welde megen Derbreden oder Bergeben gegen

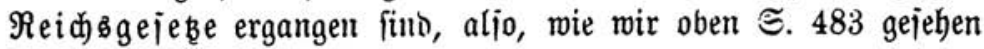
haben, nur ein Frünțtel bis eil Wiertel ber jämtlichen von beutiłuen (jeridgten exlaijentu Strajurteile. Unburüdjidjt geblieben ijt ins: bejondere bie ganze große Sruppe Der übertretungen, welde

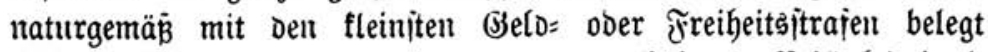

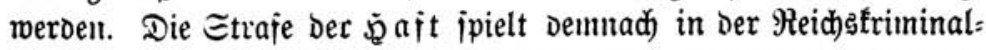

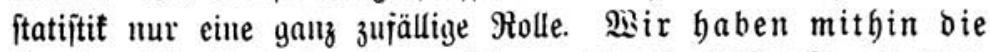
Borberridajt der turzzeitigcn freibeitsjtrafe nadge= wiejen, obne oie widtigite und häufigite der furzzeitigen Freibeitsitrafen, Die қajt, irgendoie zแ berüdiidtigen.

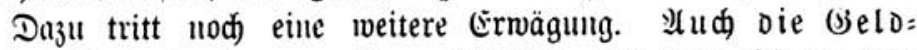
ftruje fübrt in Den meijten jällen auf Dem wiege der Etrafummandung mittelbar wieder ju turzzeitigen Frei= beitsitrafen.

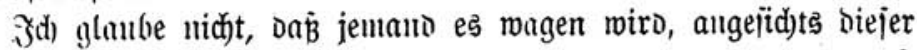

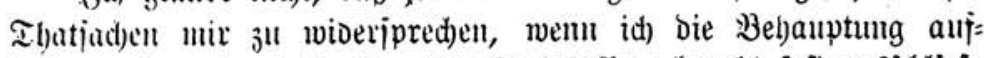
ftelle: unife gejamte heutige Etrafredtâpflege berubt fajt auşidlief: lid) auf ber tursseitigen Freiheitsjtrafe. Daraus ergibt ïch un= mittelbar oer weitere Sd)luj: wenu bie hurzseitige Freiheitß̄itraje

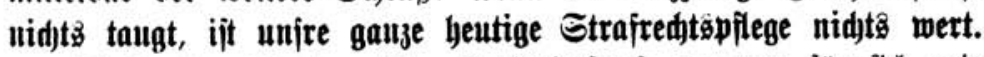

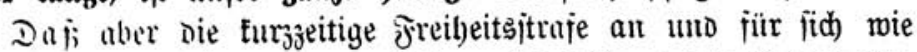
gun; bejontors bei Der gegemwärtigen Einridytung Der fleinen Ge= 
fängniiñe nid)ts taugt, barüber funt heute mohl alle Einfiditigen

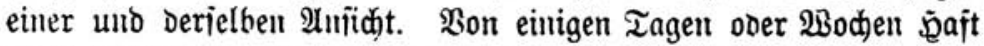
oder Gejë̈ngnis wiro wohl niemanto eine nachbaltige befiernbe Eiumvirfıng auf Dell Sträfling ermarten. $\mathfrak{u m}$ aber bie turzzeitige Freibeitsftrafe abja)redent zu geítalten, beoarf es einer ganz anbern (Einrid)tung unjrer tleinen Bsefänguifîe, als wir fie beute vorfinden, vor allemt einer ftrengen Durdhführung Des Arbeits= zmanges, ber ja mit unirer bentijen Şaftitrafe nur auşnabıssmeife (ulto aud bier meijt nur auf bem \$apiere) verbunben ift. In uniern beutigen fleinen G̈erid̆tsgefängniīen finben wir alle bie Mängel mièer, meldhe bie alten 3udhtbäujer zu Brutifätten bes

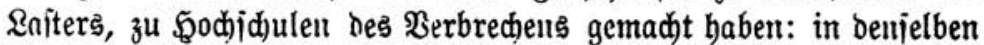

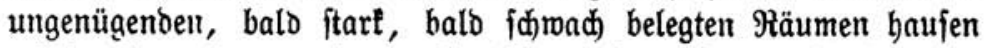
miteinamber alte uno junge Sträffinge, hartgejottene Süuber uno.

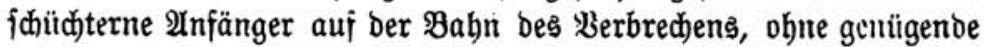

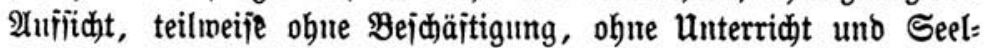
jorgye. Nur bie harte ernite Zudit ber alten Şäıjer feblt. Fö̈r ben

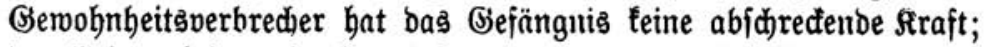

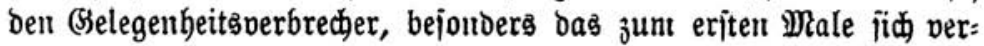
fehlende Freiheitsftrafe ift nidht mur mulos: fie faäbigt oie Red)tsordung idruerer, als bie völlige Etraflofigteit ber Berbreder es zu thun im ftalloe märe.

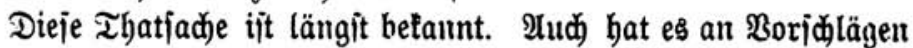

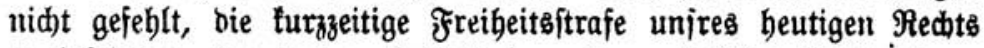
zu hejeitigen ober boch zut bejđränten. Demmod) iît bie Bejeßzgebung ber meiften Ränber, insbejonbere aud) bie bes Teutidjen Reidjes, aui inrem alten Stanbpuntte itehen geoliehen.

Ës ijt Duber leider uidat ganz überflüffig, einige Beugniije für

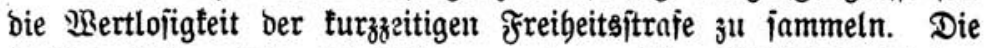

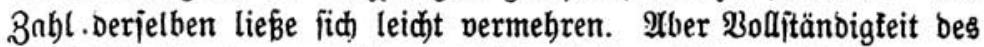
Diaterials ift es gar nidit, was id anitrebe. Dir genügt es, welm es mir gelingt, Dic oringende Hotmendigfeit einer llmgeitaltumg unịrer Strajgefę̧gebung burd) die Ä Şemäbrsmämmer nadzumeijen. Wienn meine Rejer finden jollten,

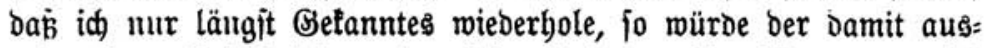

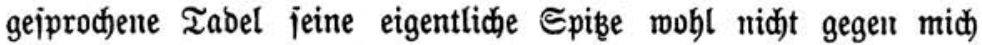
rid)ten. Solange ber "Preuzzug gegen Die turzzeitige Freibeiţjtraje" nid)t zum 3iele geführt hat, ijt es fein überflüifitges Begimmen, Das Rreuz zu prebigen. 
Sđjon im Jabre 1803 hat v. $\mathfrak{A}$ rnim in jeinen Brudjitüten über Berbredeen und Strafen $(I, 95)$ bie Morte gejprod)en:

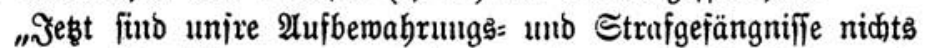
anders als Berführungspepinieren, bas meiß eil jeber; und jenes (bie Belajfung berjelben in biejem 3ujtande) bieße aljo nidts anders, als Daß man bie ßerbrecher erit in ben Жujbewabrungs= unto Strafgejänguifîen nod) idjlimmer werben laffen mollte, um jie Demuäbjt in ben Bejןerungsanftalten zu befiern, un jogar mor $a=$ (ij门) zu beffern."

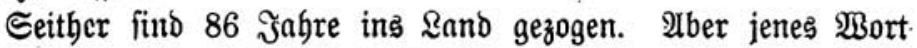
von ben "Berjührungspepinieren" ijt nidjt alt gemorbelt. NBollte man jenen Saz̧ anfïbren, ohue ben Berfajier zu nennen - man mürbe wohl ohne meiters auf einen heutigen Sejängnisobireftor als jeimen urbeber jobließen fömnen.

Denu gerabe in ben Sireijen ber preußij

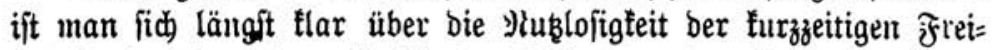

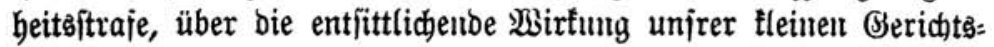
gefängniffe. Mir find diefe Stimmen von ganz bejonbern $\mathfrak{B e r t .}$

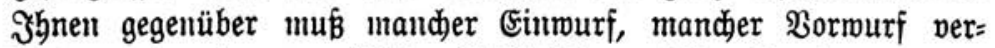

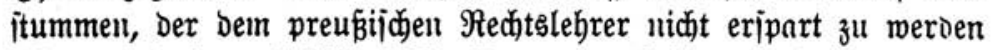
pflegt, jobald er tritijhe Streijäuge ins beilige \&ano Der Straj= red)tipplege unternimmut.

Balentiu, Damals Strafanitaltsoirettor zu $\mathfrak{B a r t e n b e r g}$ in Dit= preuken, jagte im Jahre 1869 (Das ßerbrechertum in preubijiden Staat S. 63 i.): "Man bört oft bie Zudbtbäujer, in benen die Siollettivhaft vollitreät wiro, "Brutitätten bes \&aịters" neunen. Dhne die Beredtigung biejes Epithetons abjolut in 2 brebe itellen

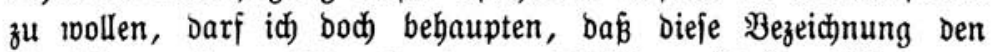
Geridtagefängnifien in einem viel böberı Dlaß̉e gebührt...

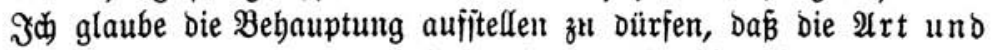

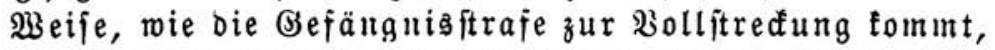

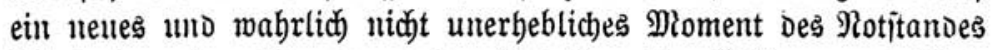

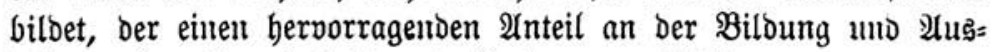
Debnung Des Gieroohnheitsperbrechertums ausübt."

Soch fräftiger bat ïđ) ungejähr um biejelbe Zeit ein anorer

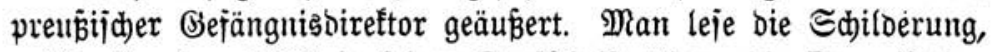
weldje Srohne 1868 in jeiner Denfjurijt über "Die Drganijation

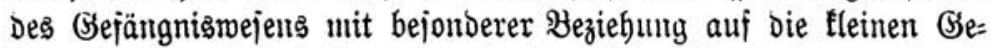

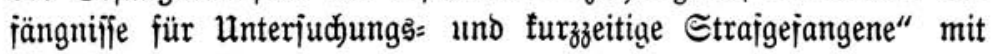

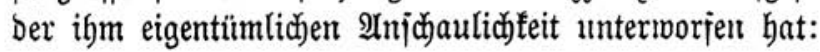


"(BSearbeitet wiro in biejen (Sefängniffen faft gar nid)t, böd)itene

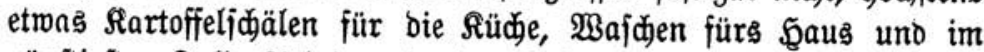
günitigiten Falle $\mathfrak{A r b e i t e n ~ i n ~ b e s ~ B s e j a n g e n t a ̈ r t e r s ~ S ̋ a r t e n , ~ m o b e i ~}$ es benn aud vorgefommen fein jod, baß̧ er fie ganz gemütlid) mit auf jeinen 2 der nimunt, was fo lange gut gebt, bis gelegentlid) ein Befangener entläuft. WSenn nul aber gar bie Bjejangenen bei ben Bürgern ber Stabt in Tagelohn gehen zum நolzipalten und Barten= arbeiten, uno abenos ins Befëngnis zurüdfehren mit $\mathfrak{T} a b a f$, jelbjt Branntwein, ben fie erbettelt oder gejtohlen, wenn baum abenos in Den gemeinid)aftlichen Räumen Tabaf geraudht, Rarten gejpielt, jelbit Branntwein getrunfen wiro, mo ifit ba bie Bstenze zwijhen Strafe und Farce?.... Das find benn bod) 3uitände...., bie mit einer vernünftigen $\Re$ echtspflege und einem georoneten Straf= vollzug unvereinbar f̈ut. Diefe Zujtänoe finden fich nicht vereimzelt in biejem oder jentem Lande, bas ift ber Durdjibnittszuftand ber

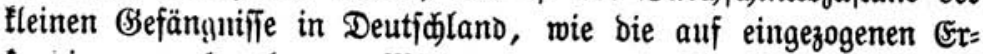
fundigungen berubenden Mitteilungen von b’allinge zur B̈entige beweijen; fie finden fid in groken Staaten jo gut wie in fleinen, im Noroen und Süben, im Diten uno ßeiten. Was bilft es benn nun, bie größeru Befängnifife zu reformieren, wenn bie Hleinern Befängnific den $\mathfrak{B e g}$ zu neuten Berbreden und zu ben 3udtbäujern bahnen?"

Wan vergleidje bamit bie $\mathscr{A} u$ sfübrungen in ber Statiftif ber unter Dem Minifterium bes Эumern ftehenden Strajanjtalten, Эabr= gang 1872 bis 1874: fie beweijen, baß̉ man an biejer Stelle bie

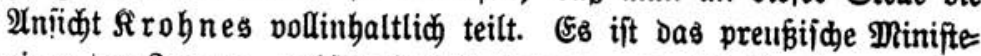
rium Des Эunern, weldes bas ßerbammungsurteil Fro fones unter= finreibt!

Aber vielleidyt ift es anbers unb beffer geworben jeit oer (S) Yrü= Dung Des Deutjdjen Reids?

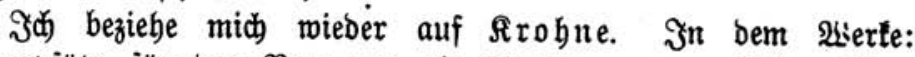
"(Brunojäßze für ben $\mathfrak{B a u}$ und Die Einriddtung von Zellengefäng=

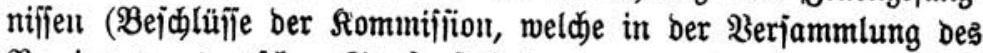
Bereins Der Deutiden Strafanitaltebeamten zu Mien am 20. Sep=

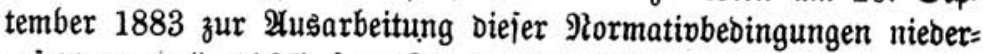
geję̧t murbe", 1885) jagt Sirohne ऽ. 40:

"13unädjit wuroen in ben Borbejprechungen all bie lang= jäbrigen und von bell veridjiebenften Seiten vorgebraditen slagen über ben maligelbaften Strafoolzug in ben fleinen Ese- 


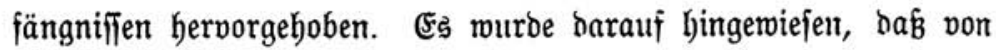
einer ernjtelt, irgeno meld)en nadjhaltigen Eimorud madjenden Straje

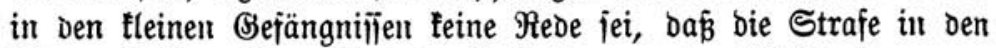

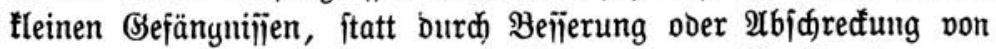
netten Berbredjent abzubaltelt, meijt zu neuten Berbred)en er= ziehe; ftatt Reipeft vor bem Strafgejęe oder ber Strafiufitiz ein=

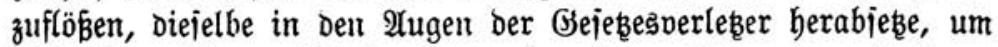

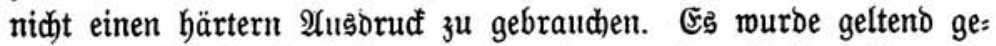

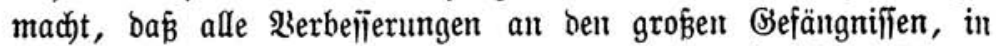
weld)e ber fertige Berbred)er eingeliejert miro, mublos fino, folange nod) Der weroende sierbred)er jeine erite, meiit furze Strafe it Den

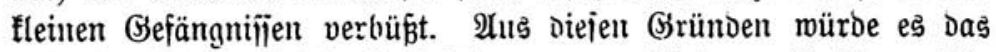
richtigite jein, auf bie Bejeitigung ber fleinen (s)efängnijie menigftens als Strajgejänguijie mit allen zu Gebote ftehenden Mitteln zu Dringen, weil aud bei einer vollitäntigen Ümgejtaltung Derjelben höd)itens einig̣e ber är(gerlichiten uno an=

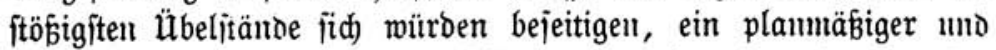
wirfjamer Etrajollzug in benjelben aber niemals wïroe ermög: lichelt lajien." ${ }^{2}$ )

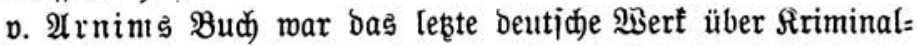
politif. Die Beit war angebrodjert, mo bie ipefulative \$hilojophie

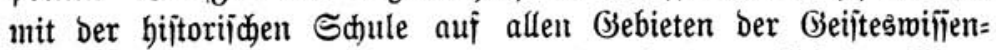

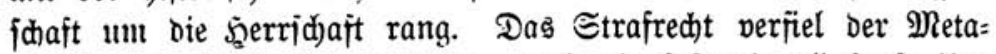
phyfif uno blieb ihr verfalleir, aud) als fait ïberall fonit ibre Serridaft gebrod)en war. Sod) heute itectt uns Sriminalijten bie Segelide \$hilojophie von ber Sdulle her in allen Bstiedern. Müh=

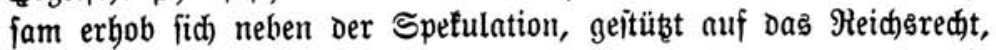

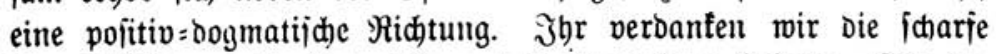

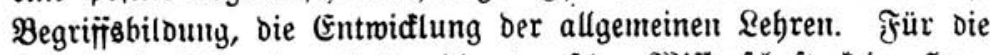

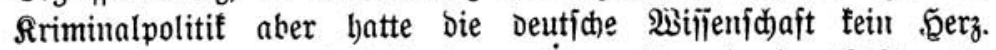
Ruhig ließs fie Die einjeitig humanitären Frreunde der Ģefännguis= verbefferung gemähren.

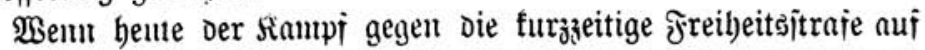
ber ganzen Rinie entbraunt ijt, jo verdanfen wir Dies einerieits dent

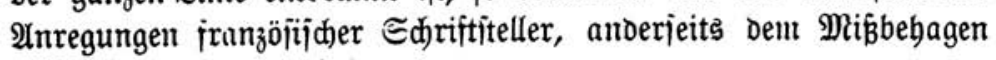
unirer beutichen \$raftifer.

2) Man vergl. aud Rrohnc, \&efrbud) Der Befängniştunde 1889, inš: bejondere $\S 44$. 
Unter ben Franzojen hat fich ganz bejondere Berbienfte $\mathfrak{B}$ oune= ville De Marjangy burd) jeinen fortgejekten Sampj gegen die furzzeitige Freiheitsftrafe ermorbent. In jeinem gropen uno bebeut= famen friminalpolitijchen ßerfe: De l'amélioration de la loi criminelle, en vue d'une justice plus prompte, plus efficace, plus généreuse et plus moralisante, 1864, finden wir faft alle biejenigen Maßregeln zur Bejdränfung ber furzzeitigen Freiheits= ftraje beiprochen, weldhe nod) beute den (Begenitand unirer $\mathrm{Er}=$

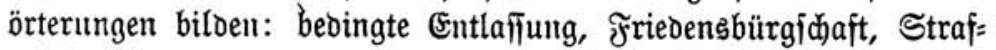
arbeit ohue (Finjperrung, ridjterlidjen Dermeis, Umgeitaltung oer Belditrafe ujw. Bis auf den bentigen Tag ift Bonneville de

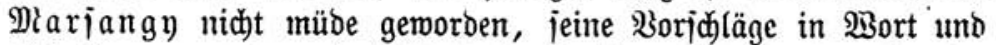
Eưrijt zu vertreten (pgl. Bulletin de la société générale des prisons XI 311).

Bonnevile be Marjangy hat einen großen uno bleibenben

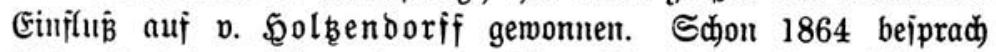

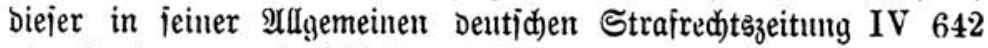
eingehend uno mit lebhafter Zuftinumung Die \$orjdläge Bonne= ville de Diariangys. Seither hat er, umermüblid)er als ein antrer, bis an jein Rebensende bie foroerungen einer einfithtigen, aber maß̧oollen Siriminalpolitif vertreten, Den Miß̄braud Der furz= zeitigen Freiheitştrafe und bie übertreibungen Der Zellenbaft be= fämpft, Sorjđläge zur Berbefferung Der Strafgejeßzgebung gemadit. Geinen leb̧ten Rebensjabren entitammen bie fleine Mlbbandolung in

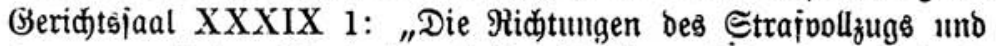
Der gegembärtige Stand ber faùjverjtänbigen Meimungen", jowie

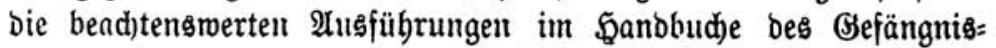
mejens I 432.

In jeiuen triminalpolitif(ben $\mathfrak{A n r e g u n g e n ~ u n o ~}$ Bejtrebungen liegt $\mathfrak{v}$. Solkendoxffs bleibendes ßerbienit; es wirb baburd) nidat gejumälert, baß̧ bie orthoonce Sdulphilojophie fie ibm als ßer= irrungen auslegte und nadtrug.

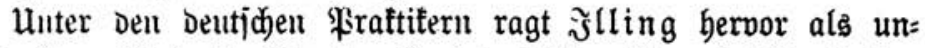
erjodroctenter $\Re u f e r$ im Streite. (Er hat es fid) nidbt veroriebent laffen,

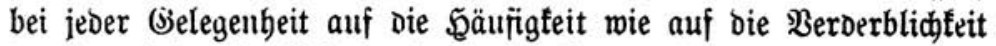

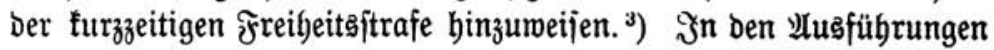

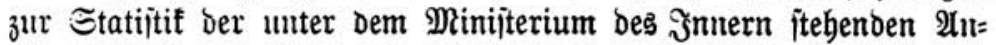

3) 노l. 3. 2. Blätter für (Sefängniştunde XV 87, XXII 148. 
ftalten ijt er wieberbolt auj bie Frage eingegangen, jeite ßebaup= tungen auf unviderleglidje 3ablenreiben ftüß̨eno. 2luf ben Эer= jammlungen bes Wereins Der beutidjen Strafanitaltäbeamten hat er jeine Stimme erboben, um bie Milde unjres Geję̧budbs und Die

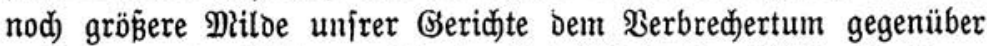

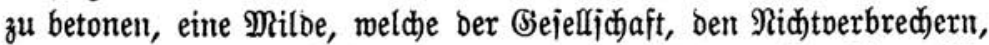

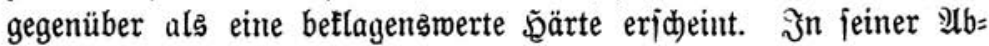

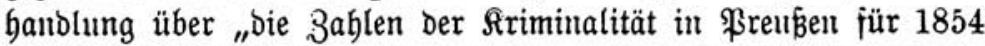

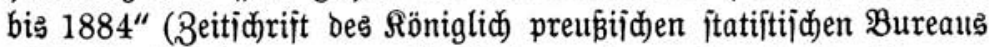
1885 ऽ. 73) hat er neue Thatjachen gejammelt und Die alten zu= jammengejtellt, um in Der $\Re u r z z e i t i g f e i t$ Der Strafen und in ber $\mathfrak{A}$ rt des Strajpollzuges bie beiden übelitände nawzumeijen, melde vornebmlid ber $\mathfrak{B}$ ermebrung Der Delifte und Der Rüđfälle Boridub leiften.

unto Slling, id) betone es, urteilt nid)t vom grünen Tijø) meg, wie man uts "\$rofejporen" das vormirft, foltbern heraus aus Der Füll'e ber Erfahrungen, bie er in jabrelanger Thätigfeit ge= fammelt, geprüft uno immer mieder geprüft bat.

Aber gar mander anore Name ließ̨e jid anfübren. Medem uno Mittelftäbt, Strofier und Sidart, Sdmölder uno

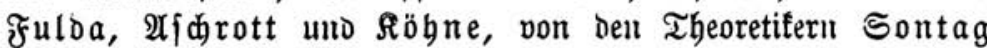
unb Sammajd), Der Srrenarzt Siraepelin ${ }^{*}$ - mögen fie in ibren einzelnen pofitiven \$orjdlägen nod) jo jebr voneimanber $a b=$ meiden, fie find bod) einverjtanden über bie Y(otmendigteit einer

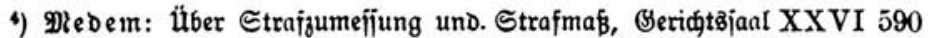

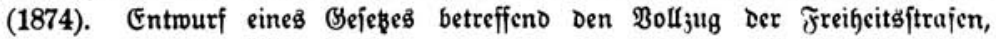
Z VII 135. Das \$roblem Der Strajzumejijung, Beriळtşaul XI 161.

Rittelftädt: Begen dic Freigeitsfitrafe 1879 und für und wider die frei= heitsiftrafen Z II 419.

Strofjer: Blätter für Bejängniştunde XXI 145.

Sidart: Die Müdfälligfeit ber Berbreder, 1881 (S. 42, 71).

FuIDa: Die Bsfängnißెverbefferung und Der Strajodljug im Deutidjen

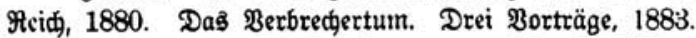

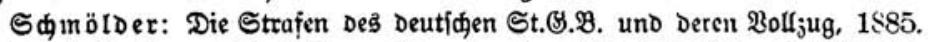

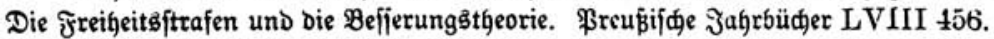

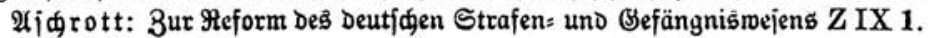

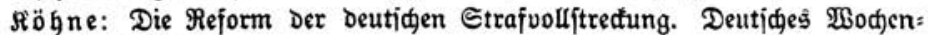
blatt, 25. Mpril 1888.

Sontag: Beiträge jur \&ehre von Der Straje Z II 515.

ฉammajd: Über 3mede und Dittel ber Strafe Z IX 449.

Rraepelin: $\mathfrak{A b j h a f f u n g ~ d e s ~ S t r a j m a p i e s s , ~} 1880$. 
grünblidłen Uumgeitaltung unirer gegenmärtigen, burd̆ bie faft augs

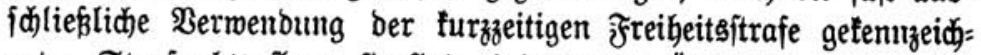
neten Etrafrectitspflege; fie finto einig in oer überzeugung, baई bie łurzzeitige freiheitştrafe fääolicher wirft als bie völlige Straflofig= feit bes §erbrechens, baß̧ wir in unjern łleinen Beridhtsgefängnifien auf Staatstojten Sdulen bes ßerbredjens unterbalten, Daß̧ eine ber

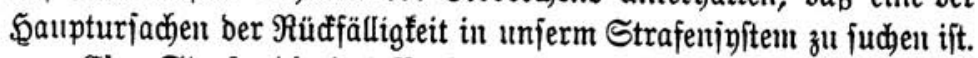

(sine Strafe, bie bas Berbredjen förbert: bas ift bie lekste und reifite Frucht ber "Dergeltenden S'ereditigfeit"!

Un no wie viele \$lbbandlungen uno $\mathfrak{A}$ ufiäbe in Zeitungen und

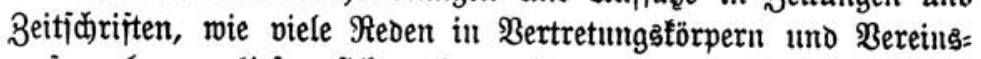
veriammlungen liebent fich noch) anreiben, menn es barauf anfäme, nid)t mur ein Stimnungsbild zu geben, fonbern bas volfitänbige Daterial zu beid)affen!

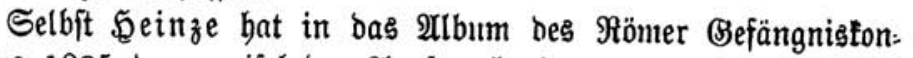
grefies 1885 ben zmeifelnten $\mathfrak{A}$ usfprud eingetragen:

"Die Freibeitsftrafe in ber Beitalt ber Einjperrung ift meit Davon entfernt, eine dem $\mathfrak{B e j e n}$ ber Strafe volfommen entfpredjende Má̧regel zu feiu; ibre $\mathfrak{B}$ eibehaltung ift nur zu redtfertigen burd) ben Mangel eines geeigneten Strafmittels."

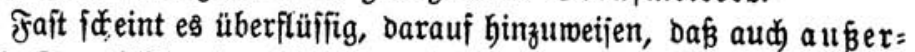
halb Deutfílanos biejelbe Eridjeimung fid zeigt: bie faft aus= fidlieplicke Bermentung ber furzzeitigen frreibeitsiftrafe, bie verberb= lide $\mathfrak{B i r f u n g}$ berielben, bie fteigenbe Erbitterung gegen biejes un= geeignete Strafmittel, bus madjiende, aber nod) unfidere Bemüben, etwas anbres an inre Stelle zu fezen.

24ud) bier taun es mir, uno mefre nod als für bas Deutide

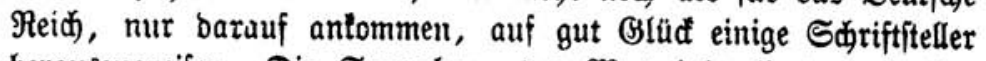
berauşzugreifen. Die Sammlung Des Daterials liegt aud bier meber ill meiner $\mathscr{A}$ ufgabe nod it meiner Mbfidt.

Beginnen mir mit Frantreid.

Der Zuftanto ber tleinen franzöfifiden Befängniffe fann als befaunt vorausgejeşt merben. Fs wiro uns nidjt überrajden, menn

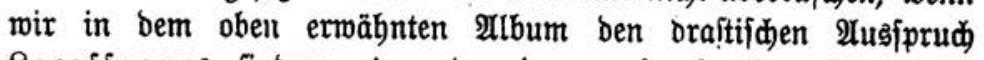
Racaffagues finben: A notre époque la justice flétrit, la prison corrompt et les sociétés ont les crinninels qu'elles méritent.

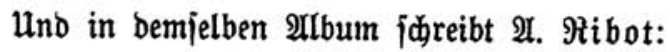

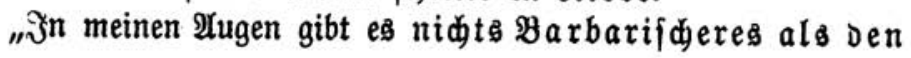




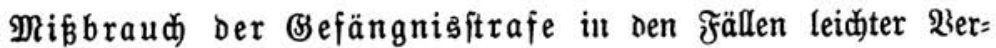

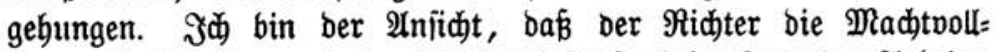
fommenheit haben muß̧, ber Befängniştrafe einige Tage der $\mathfrak{A r b e i t s : ~}$

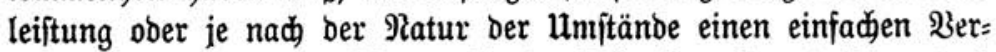

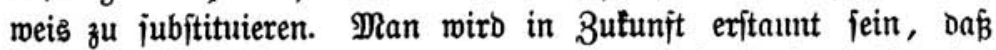
eime fo einfache und notmendige Reform Begenjtand langmährenter Disfuffion fein fonnte."

In SSarraubs und \&acajfagnes Archives de l'anthropologie criminelle III 555 äußert fid Emile Gautier allf

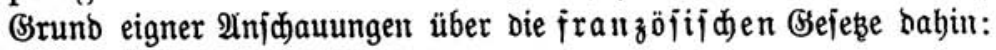

„En verité, la prison, telle quelle est organisée, est un véritable cloaque épanchant dans la société, un flot continu de purulence et de germes de contagion physiologique et morale. Elle empoisonne, abrutit, déprime et corrompt. C'est à la fois une fabrique de phthisiques, de fous et de criminels."

$\mathfrak{u}_{n d}$ im felben Sinne, wenn aud mentiger brajtijd, jagt Fermand Desportes La réforme pénitentiaire en Suèle, 1882 , S. $20:^{5}$ )

${ }_{n}$ Les petites prisons sont, en général, la pépinière des maisons centrales. Les malfaiteur's y font leur première étape; ils s'y affermissent dans leurs mauvais dessins; ils y forment de coupables relations; ils y acquierent une expérience funeste; entrés dans ces établissements pour quelque délit peu grave, ils en sortent souvent capables des plus grands forfaits."

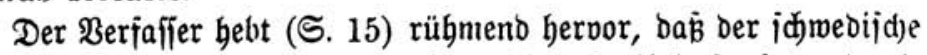
(Seję̧geber im allgemeituen die turzzeitige Freiheitsjtrafe uno oic wieberbolten Berurteilumgent nid)t zugelaijen babe: "il en comprend les déplorables effets, effets que, chez nous, tous les criminalistes, signalent et déplorent, tandisque les tribunaux semblent prendre à tâche d'en multiplier la cause."

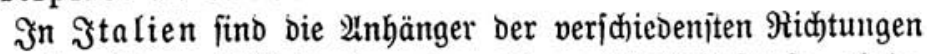
über bie Berwerflidfleit ber furzzeitigen Freibeitsjtraje einig.

5) Bgl. unter vielen andern aud \&abroquère: Bulletin XII 5ే. Dic

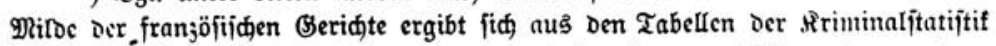
und ift non ben Bropffiegelbemahrem miederholt, aber vergeblid, g̣erügt worocn. 
Sucdint, Beltrani=Scalia, Sombrojo, Ferri, Garofalo, $\mathscr{A}$ (imena begegnen jid) bier in demielben urteile.

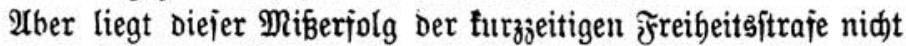

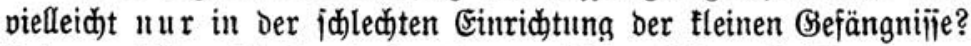

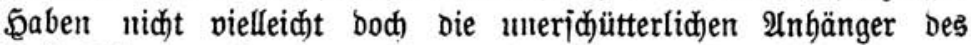
Zelleninjtems recht, wein jie von ber ftrengen Durdjüürung oer Einzelhaft Die Bejeitigung aller $\mathfrak{M} i \bar{i} \mid$ tänbe ermarten?

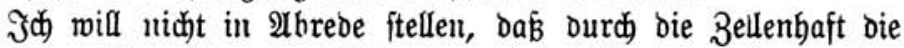
gegenjeitige : Werpeitung ber B̈efangenen fajt völlig vermieben werben tann. Das iit aber auth alles, was id) zugebe. Fine nad) Tagen

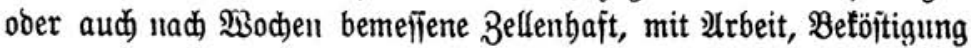
unb obue \$rügel, hat auj verfommene ober vertommende Raturen feine abidredente Bitung. Unb befiern wiro man erit redht nidjt in vierzebn Tagent.

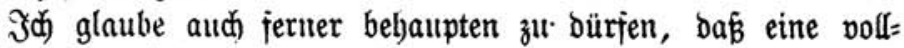
itänbige Durdfüüfrung ber 3ellenbaft in Den fleinen Bejängniү̄en in Frantrei(c), Deutidjlanto und anderswwo nod) lange auf fich marten laj̄en mirb; uno id bin für meine ßerion jogar ner jebr bejtimunten

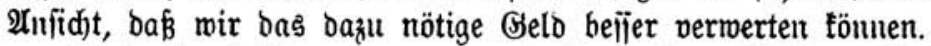

Dás aber jelbjt baın, wenn wir bie nötigen Millionen flüjijig madtell, gar nid)ts gemounen märe, baß́ ber Ourunomangel oer fur $z=$ zeitigen Frreiheitsjtraje uidot in ber Urt ihrer \$ollitrecfung, jontoern ehen in ihrer Sinrzzeitigfeit gelegen iit, oas bemeijt uns ein Blif auf Das Jiniterland Der Bellengejüngniīe.

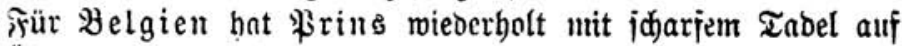

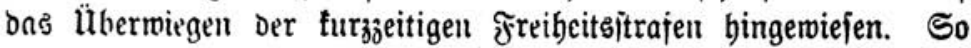
in jeiuem Sudle: Criminalité et répression 1886, insbefondere ऽ. $91 \mathrm{if}$. แnto in eitrer 1888 ano ber Revue de Belgique abge=

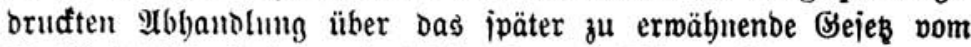
31. Mai 1888 (loi sur la libération conditionnelle et les condamuations conditionnelles) insbejondere 5.10 i. "Ces chiffres, jagt er an ber eritangejülbrten Stelle, „semblent témoigner surtout de la mausuétude du juge. Ils sont, en réalité, la preuve du formidable abus qui, chez nous comme en France, se fait des petites peines."

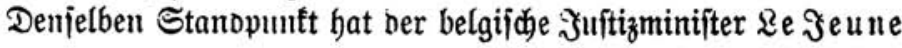
in ber Siz̧ung bes Hbgeorontenthaujes von 9 . Mai 1888 mit ben Sisortell eingenommen: nje crois, qu'on peut dire, sans crainte d'être démenti, qu'aujourd'hui l'inefficacité absolue de 
l'incarcération, lorsque l'imprisonnement n'est que de courte durée, est péremptoirement démontrée. “

$\mathfrak{U}_{110}$ nod ein paar Stimmen aus einem anbern Sanbe, befien (Einridbtungen uns ebenfalls vielfach als Pufter empfoblent worden fino, aus Englano, wo bie "\$önologie", an bie bewährteften ßor= bilder antıüpfent, bis zum heutigen Tage zahlreiche und erfabrene Bertreter gejunben hat.

Die \$iederholung turzer Freibeitsftrafen hat bie Howard

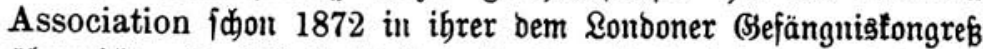
überreidjten Denfjidrift: Defects in the criminal law administration als ein foftipieliges unredt gegen bie Steuerzabler und bas $\mathfrak{P}$ ublifum im allgcmeinen (a costly injury to the ratepayers and to the public generally) bezeidinet.

Und neuerbings hat aud Tallađ, ber altbeinährte unerntiob= lide Schriftfübrer ber Howard Association, feitur itberzeugung,

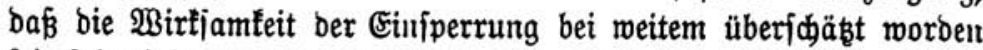

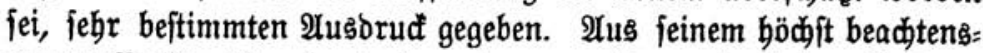
werten Suche: Penological and preventive principles (Sondon,

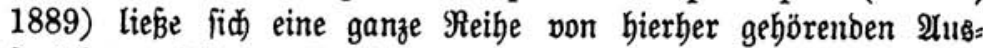
fprüd)en anfübren. So lejen wir S. 51: there is an increasing impression, amongst experienced observers, that the efficacy of even the best systems of imprisonment, has, all along, been exceedingly overestimated, and that their disadvantages, both to the State and to the criminal, have been

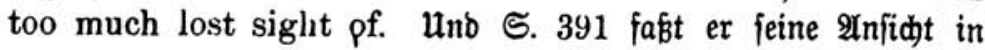
belt Worten zujammen: Progress in this departement will, as it has been here urged, be greatly promoted by an increased resort to judiciously administered substitutes for imprisonment, including conditional liberty or probation, sentences of liability to detention, but not necessarly involving that infliction; fines, and moderate corporal chastisements, as merciful and economical alternatives, in iieu of prolonged incarceration. In these matters, the present writer has united in the views approved by an increasing proportion of penologists.

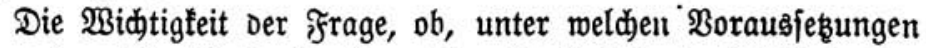
und auf melde Beife bie furzzeitige Freikeitsftrafe befeitigt ober befaräntt werben fann, wiro beute beun aud gerabe von benjenigen Mänuern betont, weld̄e, mit Dem heutigen Stande bes Befängnis: 
mejents am beften vertraut, ber Berbefferung besjelben ibre bejonbere fürjorgende $\mathfrak{A} u$ jmerfjamfeit gewibmet baben.

Sdjon auf bem eríten İnternationalen Bsefängnistongrés zu Sonbon 1872 war bie Frage:

Is it possible to replace short imprisonments and the nonpayment of fines by forced labour without privation of liberty?

Gegenftand eingehender Beratung gemejen (Report S. 155).

(Braf Forefta vertrat bie bejabende Beantwortung und fand bamit lebhaften Beifall im Sdjobe ber Berjammlung. Tallad, Eollius, John Bowring, b. Solkzendorff unterftitb̨ten ben Borjalag Foreftas, mäbrent Stevens und Diađay ibn für un=

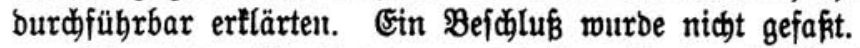

Eine abermalige Erörterung Des Begenftanbes brachte ber britte

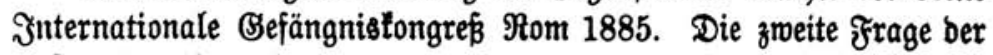
Erften 2Abteilung lautete:

Ne pourrait on pas utilement remplacer, pour certains délits, les peines d'emprisonnement ou de détention, par quelque autre peine restrictive de la liberté, telle que le travail dans quelque établissement public sans détention ou l'interdiction à temps d'un lieu déterminé; ou bien en cas d'une première faute légère, par une admonition? ( $\mathfrak{B g l}$. Comptes rendus I 179, II 417.) Wieber wurbe ber Sebante, Erfaß̧mittel für bie furzzeitige

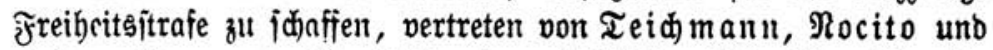
vielen andern, von allen Seiten inmpathifd begritist. 2lber über bie

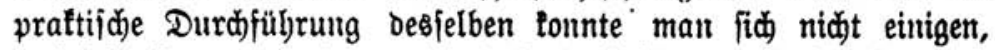

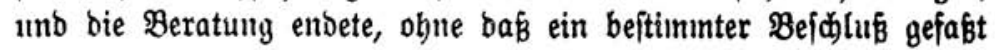
worbelt wäre.

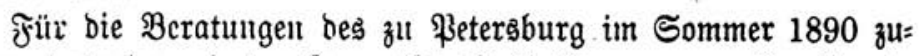
janmentretendent viertell Fiongrefies ift bie frage, nunmebr aber in folgentor fajīn, micberbolt:

Pour quel genre d'infractions à la loi pénale, sous quelles conditions et dans quelle mesure conviendrait-il d'admettre dans la législation:

a) Le système des admonitions ou remonstrances adressées par le juge à l'auteur des faits réprobes et tenant lieu de toute condamnation?

b) Le mode de suspension d'une peine, soit 
d'amende, soit d'emprisonnement ou tout antre que le juge prononce, mais qu'il déclare ne devoir pas être appliquée au coupable, tant quill n'aura pas encour'u de coudamnation nouvelle?

23on $\mathfrak{B u}$ ulfert in Postau, Dreifus in \$aris, v. Sirden= hain in beibelberg, jomie von bell Sdreiber biejer Zeilen fino (Sutad)ten itber bie frage cingeforbert worbent.

21uc) auf ber eriten, aut 7. unb 8. 2lugujt biejes Jabres zแ Brüifel abzubaltentben Berjanmlung ber "internationalen trimina= liftifden Wereinigung" lautet bie sweite ber zur Beratıng geitellteı Fragen (sie erite betrifitt bic unten beiprochene hesingte ßerurteilung Des belaijden ?tectito):

Welche Wiakregeln fann man dem Giejesgeber entpieblen, un bic 2lnmentoung des (Beiängniijes bei Lierurteilung megen leid)terer Wergebumgen eimzuịdhränten?

Die von (jarojalo uno mir üher bieie frage eritatteten

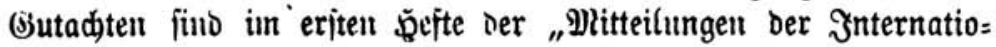

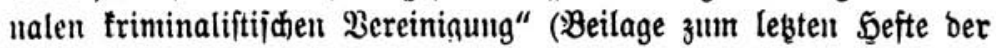
"3citict)rift") zum 2lborud gebradt.

An eingehentocr uno viclieitiger Erörterung Der Erjaßzmittel für

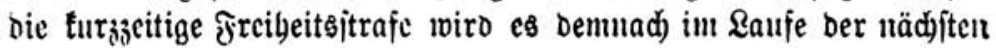
jabrc nidjt fehlen.

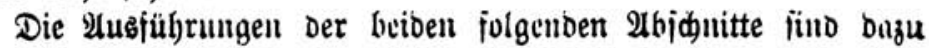
bejtimmt, Die Erörterung altzuregen uno zu föroern, nidjt iljr vor=

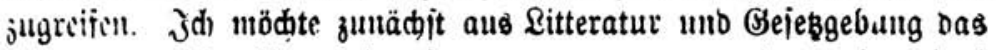
mir zugänglid)e Dlaterial zuinmmentragen, Daun aber meinc cigué

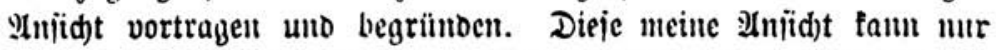
cinc vorläufige, feine entogültige jein. Wejïerer Belebrung merbe id) Dabei itets jrentig unb bantbar ju jolgen wijïcn.

VI. Die Erjazmittel Der turzzeitigen Freibeitsitrafe.

\section{Der Stallb ber Frage.}

Well Şeinze bie Beibebaltung ber Freiheitsftrafe in ber Se: ftalt ber Einjperrung überbaupt nur aus Dem Dlangel eines geeig= neten aubern Strafmittels ertlären unb redtfertigen zu tönnen meint,

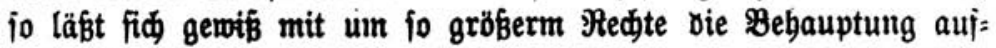
itellell, baß Die Bejeitigung ober \$iejdräıtung Der turzzeitigen Frei= beitsjtraje in bem \&ugenbliđe erfolgen $m u \hat{\beta}$, in weldem. 
jein wirb, anbre Strafnittel ober frafwettretenbe Eintiditungen an

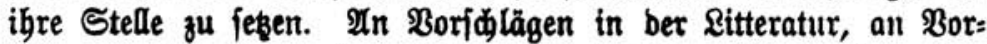

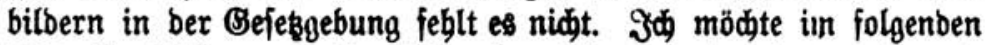

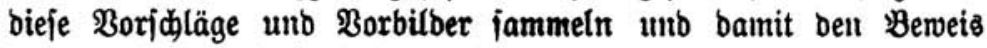

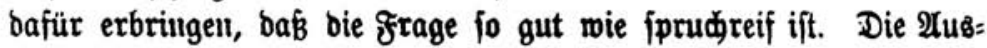
fübrung meiner eignen $\mathscr{2 n}$ ifidt bleibt einem meitern $\mathfrak{A b}$ idnitte vor= behalten. Dabei laffe iđ, bem 3mecte meiner Alısfübrumgen ent= ipredeno, bie Frage zunäđit gänzlich unerörtert, ob es nidbt möglid) wäre, bie ber furzzeitigen Freibeitøీftrafe unirer Tnge aubaftenben Mängel burch eine veränberte (Seftaltung bes Strafvollzuges zu be= jeitigen.

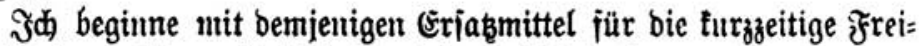
heitsftrafe, meldjes, obgleid) ber Zeit nadj bas leşte unter bell vor=

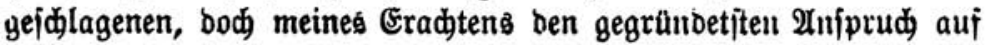
ernite Beadtung zu erbeben beredtigt ift.

\section{Die Alufekung ber Strafoollftredung. (Die jogenante "bebingte Berurteilung".)}

Beht man von bem Bebanten aus, Daß̧ bie Tage unt গädte,

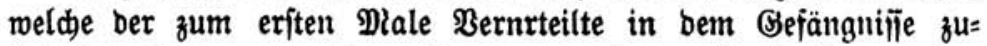
bringt, zujammengemorfen mit graugemorbentu ßerbredjern, obue Beidäfitigung uno obne Iufiid)t, in zablreiden, ja in ben meiften Fä̆llen entideidend find für jein jpäteres \&eben; onß̧ jein Elyrgejühl gebrodjen, bie Sd)ell vor ber Strafe vernidjtet ift; Daß̧ bie erjte

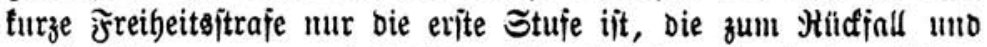
Durd) Diejent zum unverbejïerlid)en SSerwobnbeitoverbrechertum fübrt;

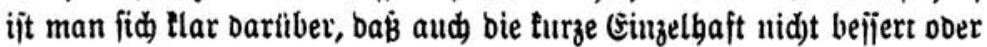

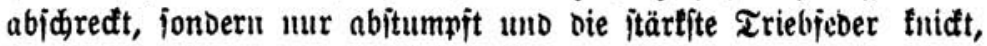
weldje von ber Serbredjerlaufbahn zuriälbält, bie 2ldtung vor fid)

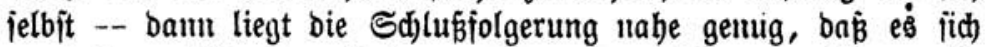
empfeblen mübte, Dent (Erftberurteilten eine Frijt zu getwähreı, ebe bie (Bejelljdaft inn preisgibt, nod) einmal jein Sdjidjal ihm in jeite

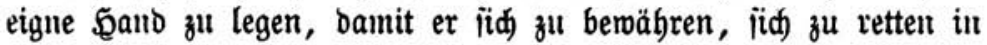
Der Lage jei.

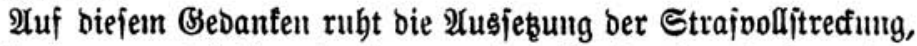
mie idy fie genannt babe, ober ber sursis a l'exécution de la peine, bie condamnation conditiunnelle, ber conditional release, Die sospensione della pena. das \$robationsjyjtem, wie man antersıo iic) auङzuorüdfen pịlegt. 
Das Berbienft ber exften थnregung biefer Einridjung gebührt Bérenger. İn einem Beję̧voridblage (Bulletin de la société générale des prisons VIII 550) sur l'aggravation progressive des peines en cas de récidive et sur lemr atténuation en cas de premier délit, welden $\mathfrak{B}$ érenger im Jahre 1884 bem Senate madjte, finben mir folgenbe Beftimmung:

${ }_{n}$ En cas de condamnation à l'emprisonnement, si les circonstances sont atténuantes, si en outre l'inculpé n'a pas subi de condamnation et que sa conduite antérieure, sa situation, ses marques de repentir paraissent offrir des garanties suffisantes, les tribunaux correctionnels sont autorisés, après avoir prononcé la condamnation, à ordonner par décision motivée qu'il sera sursis à l'exécution de la peine, tant que le condamné ne donnera pas de nouveaux sujets de plainte.

En cas de seconde condamnation dans le délai de cinq ans, la première peine est d'abord exécutée et ne peut se confondre avec la seconde.

Son exécution commence à courir du jour de l'arrestation."

Die Ausfekzung ber Strafoollitreçung führt mithin zur Straf: freibeit, wenn ber Berurteilte im Saufe ber nädjitell fünf Jabre nidht abermals eine ftrafbare \$andung begeht.

Der ßorjळlag fanb bie 3uftimmung bes mit feiner Beratung betrauten Senatsausidunfifes. Dabei ift es bis zum Arugenblide geblieben. $\mathfrak{A} b e r$ bie von $\mathfrak{B}$ érenger gegehene $\mathfrak{A n r e g u n g}$ f́beint auf frudbtbaren Boben gefallen zu fein. Wieberbolt taudten über= einjtimmenbe Borfalläge allf. So in ber fogenannten loi du pardon, melde von $\mathfrak{M} i d$ aux bem Senat vorgejdlagen uto non biejem it ber Sikzung vont 12. Dezentber 1885 in Ermägung ge: zogen wurbe (Bulletin $\mathrm{X} 259$ ). $\Im \mathfrak{n} \S 2$ finben wir, ganz wie bei Bérenger, ben „sursis à l'exécution de la peine ${ }^{*}$. Uhynlid in bem von $\Re$ eybert uno Benoffer im Sabre 1886 an bie zweite Sammer geridjteten ßorid)lag (Bulletin X 1091), bod) ift bier bie Faffung eine etras anore, und unterideibet fid von berjentigen Bérengers insbejonbere burd) einen bebentliden Mangel an Slarbeit und Beftimmtheit. $\S 1$ verfïgt:

,Les tribunaux correctionnels, appréciant la gravité des délits et la valeur morale des délinquants 
traduits devant eux, pourront décider que la peine encourue ne sera pas appliquée et ordonner la mise en liberté suspensive des condamnés: "

Eingehend wurbe bie Frage aud̆ im Sdiope ber Société générale des prisons erörtert. Die erfte 2rbteilung ber Befell=

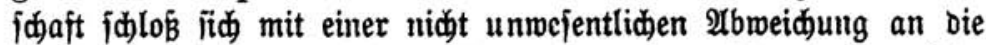
von Bérenger gemählte Faffung an. Der Eingang ber ' ftimmung jollte lauten: En cas de condamnation à un emprisonnement de moins d'un mois (ujw.) ßei ßerurteilung

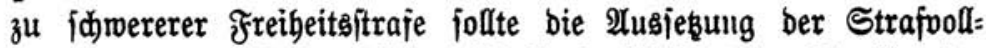
ftreçung ausgefobloffen bleiben (Bulletin XII 150). Die 2Inträge ber Arbteilung find, joviel id meí, in ber Bollverfammlung ber (Sejellijaait nod) nidbt zur Beratung getommen. Dod hat iid unter aubern Rabroquère (Bulletin XII 62) für biefelben auss= geiprodert.

Jnzıijiłen hatte Bérengers Bebaute in Belgien rajめe uno

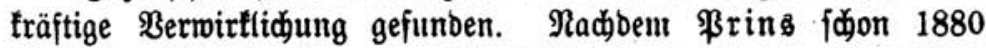

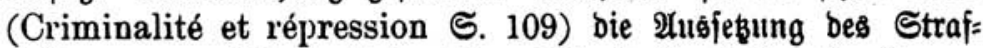

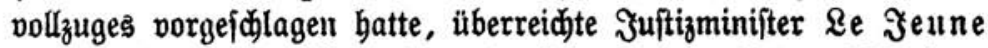
in ber Siz̨ung bes 2 (bgeoronetenbaujes voin 24 . März 1888 einen Beję̧voridlag betreffento Die Einführung ber bedingten Ent= laffung und ber bebingten Berurteilung (condamnation conditionnelle). Die Begrünoung bes Entwurfs betont, bie Birfungelofigfeit, ja Sdäblidfeit ber turzzeitigen Frreibeitsftrafe. Die Berbandlungen ber beiden .̧äujer im Mai besfelben Sabres brachten teine neuen Befidtspuntte. Unter bem 31. Mai 1888 murbe bas neue Befes veröffentlidt. Wir baben ben framzöfijden Wortlaut bes gangen Bejeß̧es oben S. 340 unitgeteilt; ber uns bier allein intereffierenoe $\mathfrak{A r t}$. IX beftimmt:

${ }_{n}$ Les cours et tribunaux, en condamnant à une ou plusieurs peines, peuvent, lorsque l'emprisonnement a subir, soit comme peine principale ou subsidiaire, soit par suite du cumul de peines principales et de peines subsidiaires, ne dépasse pas six mois et que le condamnén'a encouru aucune condamnation antérieure pour crime ou délit, ordonner par décision motivée qu'il sera sursis à l'exécution du jugement ou de l'arrêt, pendant un délai dont ils fixent la durée, à compter de la date 
du jugement ou de l'arrêt, mais qui ne peut excéder cinq années.

La condamnation sera considérée comme non a venue si, pendant ce délai, le condamné n'encourt pas de condamnation nouvelle pour crime ou délit.

Dans le cas contraire, les peines pour lesquelles le sursis a été accordé et celles qui font l'objet de la nouvelle condamnation sont cumulées."

Die Bebingungen, unter meldjen bie Ausfekzung bes Straf: vollzuges bemilligt werben fann, find nad) bem belgifden (sejeke mithin bie folgenden:

1. Die erfannte Frreibeiteffrafe Darf bie Dauer von 6 Monaten nidht überīteigen.

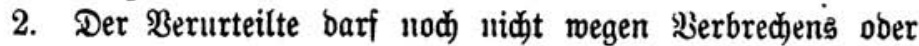
Sergebens verurteilt moroen jeir.

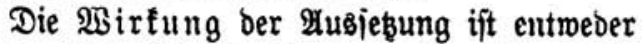

1. Straffreibeit, wenn ber Berurteilte mäbrend bes im Urteil beftinmmteri, fülif Jabre niemals überiteigenden Zeitraums feine neue Berurteilung wegen \$erbrechens ober ßergebens erlitten hat; ober

2. nađträglide Bollftređung ber zuerfaunten Strafe, menn eine joldje Serurteilung cintritt.

Begenenüber bell Boridlage voll Bérenger zeidult fid bas

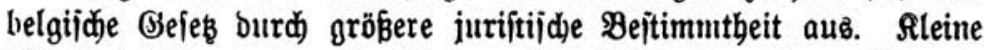

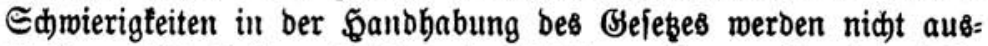
bleiben. Bei befierer Faffung bes SBejęzes tönnen fie aber leidyt vermieben merbent. So entíteht bie fdon wäbrent ber Beratung des Entrutris vol! bem $\mathfrak{A b g e o r d u e t e n ~} \mathfrak{B o e f t e}$ (Siß̧ung vom 16.

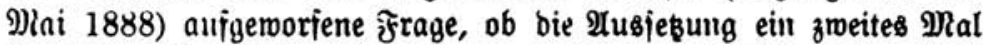
bemjentigen beroiligt werben tönne, weldher nad) 2Ablauf ber Frift eine neue ftrafbare \$anblung begangen bat. Pinifter \&e Jeune ijt allerbings ber IInfitht, baß̄ biefe Frage ohne Zmeifel verneint

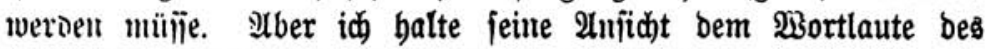
(j) jęzes gegenülier für ummöglid). Die Berurteilung foll als „non avenue" betrad)tet werden; bas fami nid)ts anbres heiken, als baßs fie red)tlid) nidjt mebr vorbanden ift. Eine nidjt vorbanbene Ber= urteiluug aber ijt teine Berurteilung. İd febe nidjt eill, wie man ïber biejes Bebenfent binmegfommen will. Bölig untlar bleibt

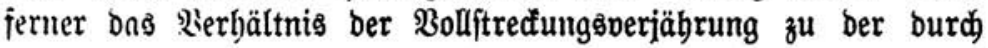




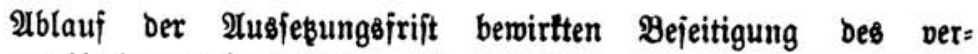
urteilenben Erfenntniffes. Die verjdiesene Dauler biejer unb ber

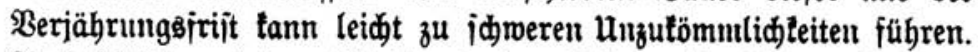

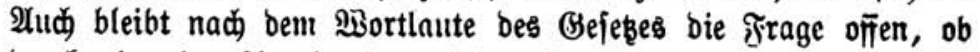
burd eine im $\mathfrak{A} u s$ lande erjolgte Serurteilung bie Bewilligung

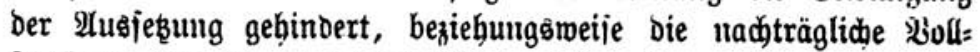
ftreçung Der Etrafe herbeigejübrt wiro. Durc Begnabiguıg

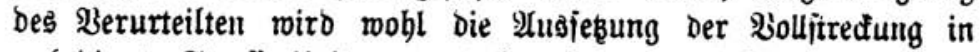
unbebingte Strä̈reibeit vermanbelt: aber ganz bejtimmt geht bas auts bem seję̧e nidit hervor und aud in bem fralle ber $\mathfrak{B e}=$ guadigung erhebt fid bie frage, ob bei ßegehung eines neuen

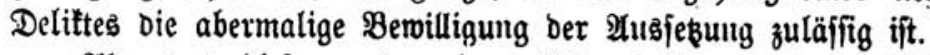

2ther trok biejer uno anorer Mängel bebeutet bas belgijde (B)

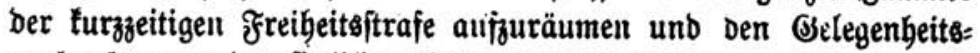
verbred)er vor ber fittlident Berberbnis zu fdikzen, meld)e ein nach

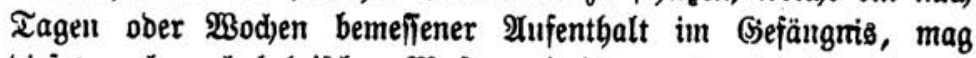
biejes aud nach belgijđem Pufter mit ber genügenben 2 nzahl von Einzelzellen verjeben fein, notwentig mit jï. bringt.

Das belgijhe Bejes voin 31. Dai 1888 bat benn aud in Der ßiffenfadaft bie ihm gebübrenbe ßead)tung gefumben. Jn ber

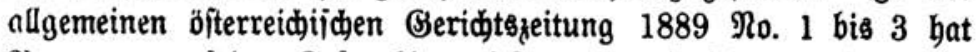
Bruuner nuf bas Gefę̧ hingemiejen uno mit jeiner 3 utimmung

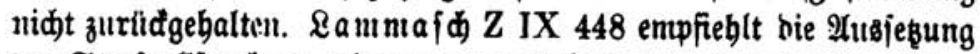
Der Strafooljtredung mit ober obne $\mathscr{2}$ ufferlegung einer Friedensbürg=

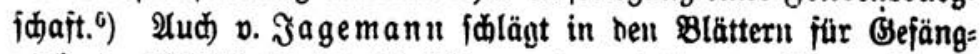
nistunde XXIV 17 bie Einjührung ber "bebiugten Berurteilung" im Sinne ber belnijळen Esejęgebung vor, bemertt babei aber, baj bie obere Erenze von fects Mlonaten "pielleidt" zu hod gegriffen

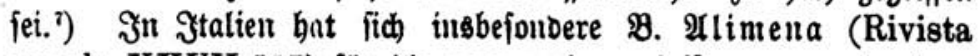
penale XXVII 557) fïr bie sospensione della pena neben bem ridjerliden Berweis ausgeiproden. Daß̧ unter ben Beratungs: gegenftänden für ben vierten intermationalen (jsejüngnistongreß (\$etersburg 1890) Der sursis à l'exécution jï bejinbet, babe id bereits oben Є. 753 angeführt. $2 u$ bie erite ßerjammlung ber

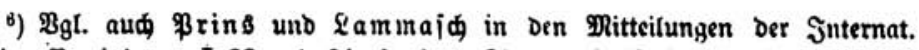
frimin. Bereinigung I 28 und 34; jowie v. $2 i_{3} 3_{t}$ bajelbft I 44.

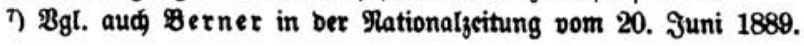


Snternationalen triminaliftifiden Bereinigung wiro fich, wie bereits bemertt, mit ber ₹rage bejđäjtigen.

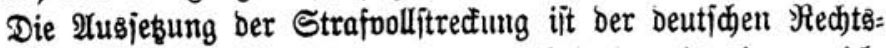
pflege vor 1870, insbejonbere ben \$olizeibeböroen burdjaus nidjt

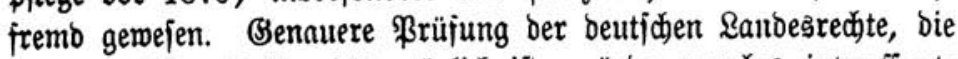
mir an biejer Stelle nidjt möglidj ift, würbe mandjes intereffante Ergebnis zu Tage förberı. Aber nicht unterlaffen taum ich es,

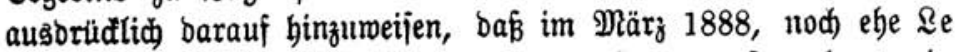
Jeune ben belgijd)en Sammern jeinen G'ejekentwurf vorlegte, ein

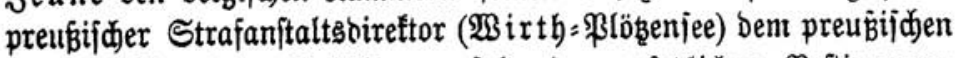
Juftizminifter die Einfübrung folgender gejeblider Beftimumung voridilug:

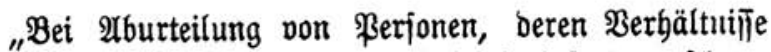

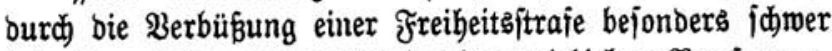
betroffen müroen, namentlid bei jugend liden ßerjone»,

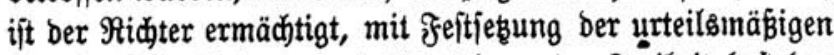
Strafe, falls bieje nur in Entziebung Der Freikeit bejteben tann, auşzuipred)en, baß̧ bie Straje vorläufig nid)t voll= frrectt merben joll, jeboch nur in bem falle, menn ber 2rbgeurteilte jum eritenmal gerichtlidy beftraft mirb unb bas urteil auj nidbt läıger als eituen Mronat Straf̧zeit lautet.

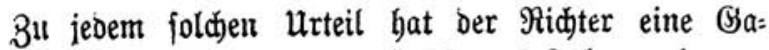
rantiefrift pon mindejtens 2 und hödjtens 3 Jahrell, die voun Tage bes Urtei(ळausijpruches an gered)uet läuft, feitzuję̧en.

„Iษnerbalb biejer Barantiefrijt barf ber vorläufig Irbgeurteilte vor feinem beutiden Ssericht wegen irgeno einer ftrafbaren §anblung zur Beftrafung foumen.

\$at er biejer Bebingung genügt, fo gilt bie vorläufig nid)t vollftrectbare Strafe als verbüpt.

Sat er iid) innerbalb ber (Jarantiefrift mieder itrafbar gemad)t, jo wirb bie vorläufig nidjt volljtrectbare Etraje

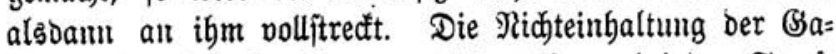
rantiefrift bilbet für bie neue $\mathfrak{A b u r t e i l u n g}$ bei ber Straf= ausmejiunt einen Ģrund zur Strafichärfung.

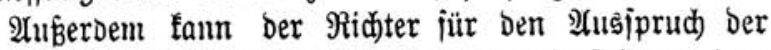

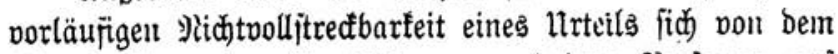

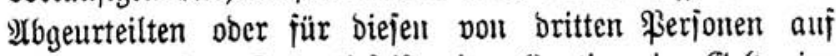
die Dauer ber Garantiefrift eine Saution in Belo im 
Betrage von 10 bis zu 10000 Marf beftellen laffen. Die Siaution ift zur Staatstaffe verfallen, wenu bie vorläufig nidit volliftrectbare Strafe bod nod) zur Bollitrediung fommen mupte; iie miro zurüdgegeben, weln bies nidit ber Fall gervejen ift."

Die Begrünoung bes Boridlages jteht auf bemielben Stand=

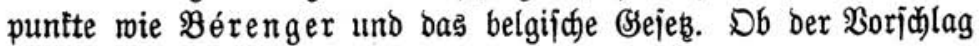
irgend meldye Beadjtung gefunden hat, ift mir nidht betannt.

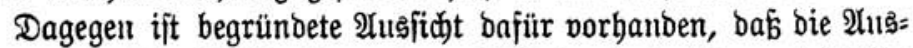
jekzung ber Strafpolfitrefung Demnädjit in bas öfterreidifdue

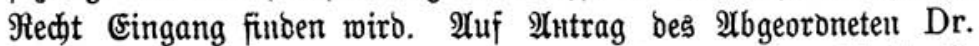
Bareuther hat Juftizminifter Sraf Sめönborn am 29. Diai b. J. fotgenden Sseję̧entwurf Dem Albgeoronetenbauje vorgelegt:

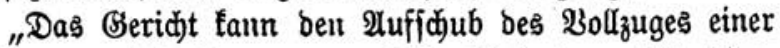
zuerfaunten, bie Dauter von jechs Monaten nidht über=

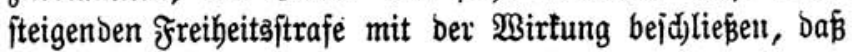
die Strafe als abgebübt anzujeben ift, menu Der Berur= teilte inmerbalb ber vom (Serid)te feftgejekten 3eit, weldae die Dauer von brei Jabren nidjt überiteigen oari, eil Berbrechen ober Bergeben nidht begangen lyat.

Diejer Bejdluß fann nur bei \$erjonen ausgeiproden merben, welde megen Berbredjens ober $\mathfrak{B}$ ergebents nod) uidt verurteilt moroen fino, von benen mit Brrund Beffe= rutg zu erwarten ijt, unb beren Seimatęangebörigfeit jejt= geftellt ift.

Dieje Beftimmung gilt niat von Freibeitsjtrajen, meldee in Fulle ber Uneinbringlidjeit von Bselbitrajelt an beren Stelle zu treten haben.

Nad) Irblauf ber im Bejdluk angegebenten 3eit hat

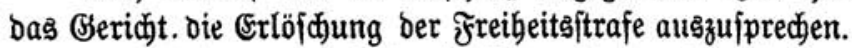

Der Bollzug von Nebenjtrajen und Der Eintritt Der

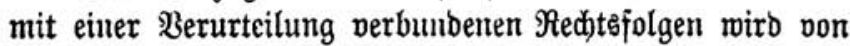

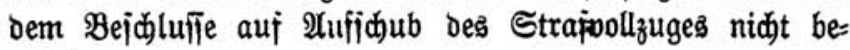
rübrt.

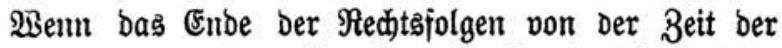
มbbüfung ber Strafe zu berect)nert ift, fo tritt biejes Enbe mit bem $\mathfrak{A}$ siprude bes (seridtes auj Erlöjdung Der Strafe ein.

Für das Einfübrungsgeję̧: Der Bejdluß auf 


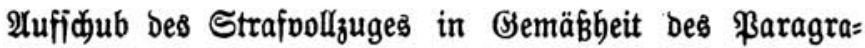
phen bes Strafgefezes muß bei ßerfündung bes urteils eröifinet merbelt.

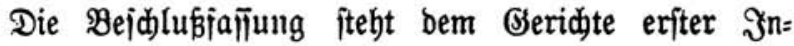

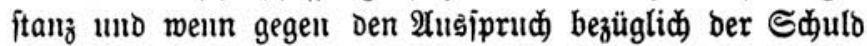

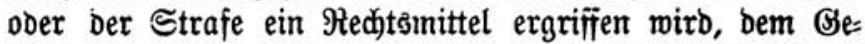
ridite zu, meldes über die abzubüßpende Freibeitsftrafe zu entidieiden hat.

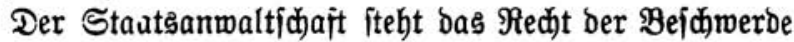
gegen ben Beid)luß auj 2Ufidjiebung bes Strafoolzuges

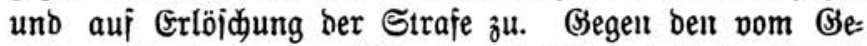

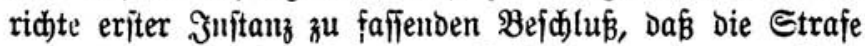

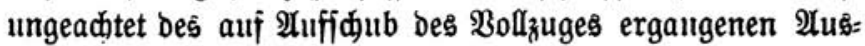
iprudjes in \$olzutg zu jeken ift, hat ber Berurteilte oas Bejdymerberedt.

Die Bejumeroe, weldhe biunelt brei Tagen nad) $\mathfrak{B e}=$ tanntgabe bes Bejdlunjes anzubringen ijt, geht gegen $\mathfrak{B e}=$

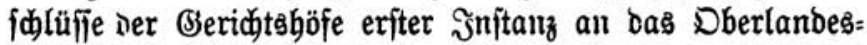
geridt) uno gegen Bejdlüjīe ber Bezirf'sgeridjte an ben (Seriditehof erfter Jnftanz."

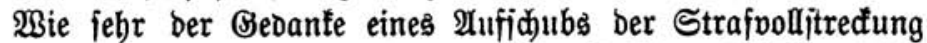
in ber \&uft liegt, beweift enolich nod) eilt flüditiger :Slid auf bie

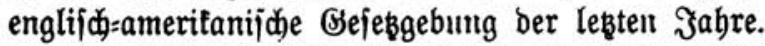

In Mañad)uffetts (Bereinigte Staatell) murde bas fidon feit 1870 gegen jugenoliche ßerbredjer zur 2htmentung gebradte Proba-

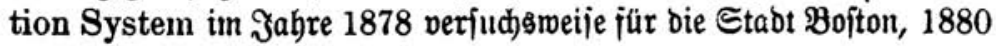
für ben ganzen Staat aud auf Ermacjiene ausgedebnt. \$eın Sofipmung vorbanben ijt; baß̧ Der Angetlagte aud obne Beftrafung fid) beffern miro, tann auf 2 ntrag Des Probation Officer (eines pon Dell Bebörden bazu bejtellten Privatmanues) ber (Seridbtslof of erlauben, baf, anitatt ber \&burteilung, bie @tellung unter „Probation" eintrete. Der $\mathfrak{A n g e t l a g t e ~ f t e h t ~ i n ~ b i e j e m ~ F a l l e ~ w a ̈ h r e n o ~ b e r ~}$ vom Beridbte bejtimmten, zmijhen 2 und 12 Monaten auşçeme

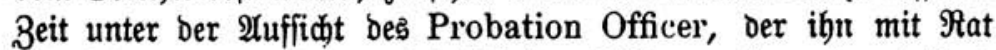

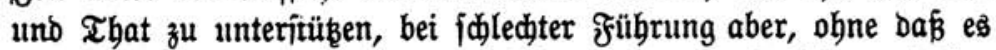
eines Shaftbefehles bedarf, zu verhaften und vor Beridit zu ftellen hat. Diejes fann nunmebr entweber mit ber 2rburteilung vorgeben ober irgend eine andre im Gejęze zugelaffene Anorbnung treffen ${ }^{8}$ ).

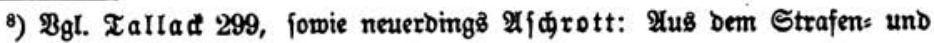

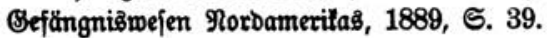


Die guten Eriolge biejer Einridhtung veranlaß̧ten bie Howard

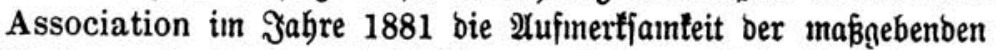
ßerjonen Englanbs auf biejelbe zu lenten. Dieje Bemübungen fübrtent zıl cinem von Howard Vincent eingebradjten Esejeşentwurf, weldyer im Jabre 1887 als „The Probation of first Offenders Act“ (ङ̈eję̧ vom 8. Aluguit 1887) angenonunen muroe.9)

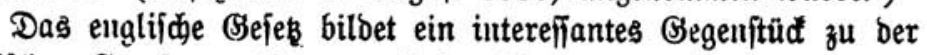
belgijden Condamnation conditionelle.

Der Probation of first offenders act pom 8. Iuguft 1887

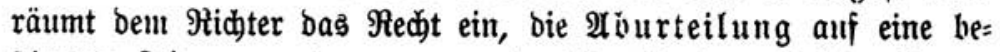

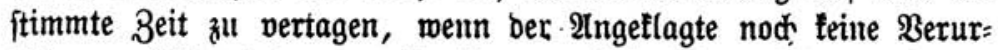
teilung erlitten bat, menn bie ibın zur \&aít gelegte $\mathfrak{L}$ bat nidjt mit einer höhern als zmeijäbrigen Befängutisîtrafe beoroht ift, unt wenn enolid, ber 2lngetlagte fid über einen beftimmten \$obnfib und ge: nügende Uuterbaltemittel aușeifen tann. Der Freigelaffene muß fid, mit ober obne Bürgidaftaleijtung, verpflichtert, auf ßerlangen fid mieber vor (Beridyt zu ftellell. Die aberınalige Begehung eimer ftrajbaren Sandlung bat Feftnabnie und aburteilung zur Frolge ${ }^{10}$ ).

Dhue Zmeifel veroient bas belgijde Bejeb Den Borzug vor bem

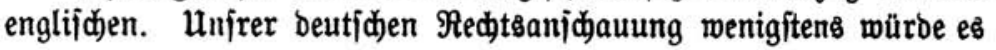

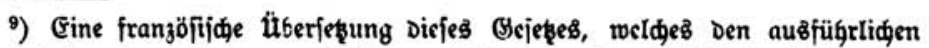
Ramen hat: "An act to permit the conditional release of first offenders in certain cases", findst fich (mit einer turzen Einleitung von albert Bigot) im Annuaire de législation étrangére XVII 52.

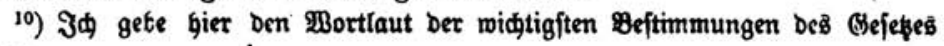
mieber.

In any case, in which a person is convicted of larceny. or false pretences, or any other offence punishable with not more than two years imprisonment, before any Cuurt, and no previous conviction is proved against him, if it appears to the Court before whom he is so convicted, that, regard being had to the youth, character, and antecedents of the offender, to the trivial nature of the offence, and to. any extenuating circumstances under which the offence was committed, it is expedient, that the offender be released on probation of good conduct, the Court may, instead of sentencing him at once to any punishment, direct that he be released on his entering into a recognizance, with or without sureties, and during such period as the Court may direct, to appear and receive judgement when called upon, and in the mesntime to keep the peace and be of good behaviour.

The Court may, if it thinks fit, direct that the offender shall pay the costs of the prosecution, or some portion of the same, within such period and by such instalments as may be directed by the Court. 


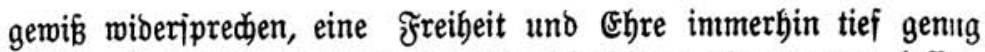

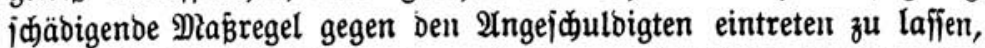

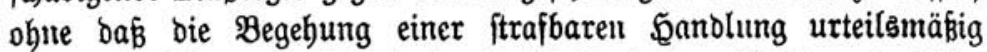

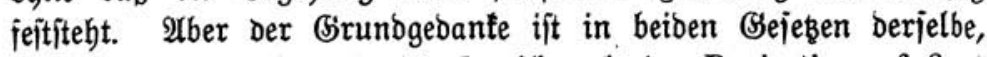
unঠ bas fällt um fo mehr ins semicht, als der Probation of first offenders act bei ber Beratung bes belgifichen Beję̧es gäızlidi un= ermäbnt gebliebent ijt, mohl aud bamals bent makgebenden \$erjonen noc) nicht befanit gemorben war.

\section{3mangsarbeit ohne Eiliperrung.}

Der squalor carceris, ber Sđamuz̧, bent ber entlaifene (Se= fangetre alts ber Strafanitalt mitbringt und von been er jein \&ebelt lang feine Seele nid)t mieber freimaden fann, läßjt fid vermeiden, mein es gelingt, den Eharatter der Strafe zu mahren, ohne ben

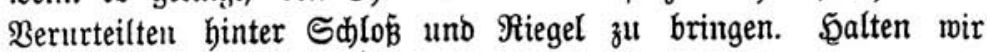
Duran feft, Daß̧ bas, was ber Freiheitsjtrafe beffernde mie züdjtigente Mirfung verleiht, Der $\mathfrak{A}$ rbeitszmang ift, jo entitebt bas \$roblem, ob es nidjt möglid jei, oent $\mathfrak{2}$ rbeitşzmang feitzuhalten, aber auf bie Einjperrung zu verzidjten, Den Siern zu bebalten und bie Sdjale megzumerfen.

Die 3mangsarbeit ohne Eimperrung ift ber (Seję̧gebung nidht fremt. Es ijt teine Reuerung, Die in Borjoblag gebradt mirb. Fajt in allen Rändern ließse fid) an bejtebende Einridtungen an= tnüpien.

$\mathfrak{2} n$ eriter Stelle ift hier an bie Shandarbeitsitrafe in bem G'e=

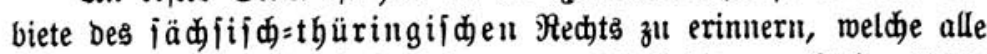
Waandlungen ber Strafgejęgebung von 1698 bis zun Jabre 1870

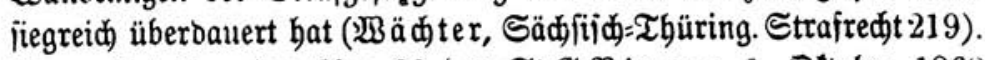
Es genügt bier, ben 2 rt. 23 bes St.ङ.'.'? vom 1. Dttober 1868 anzuiühren. Derielbe lautet:

„2luf Şandarbeitôfifraje ift niemals bas Erfenntuis zut ridoten. (5s fann jeood) bei (3)efängnisftrajen, welche im

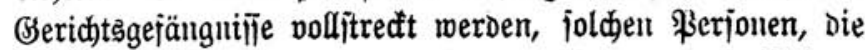

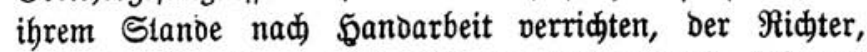
meld)c die Straje zu vollitrecfen hat, bieje Strafe, injoneit hierzı Belegenbeit vorbanben ift, ourd) Sandarbeit verbüben laifien.

Cyedod joll in jebem einzelnen Falle bie Strajarbeit

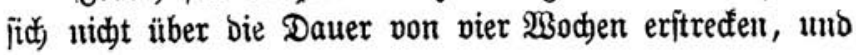


bei höber anjteigenden Strafen ber übrige Teil ber Straf= zeit burd) Befängnis verbüßjt merben.

Die Sandarbeit miro an jedent Tage in ber Dauer Der orţ̧ublichen Tagelohnarbeit geleiftet, babei jeooch bic ßod)e zu jects 2 rbeitstagen gered)net.

ßerionen, meldhe ibren unterbalt mit S̆andarbeit

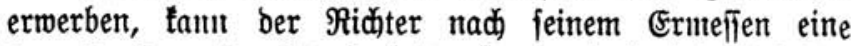
unterbreçung ber Strafarbeit geitatten, bod) fint biejelben

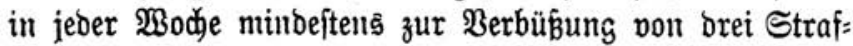
tagen anzubalten."

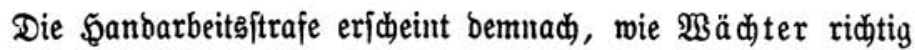
betont, alş ein "Surrogat der Bsefängniştrafe". Daß̉ fie fich) be= wäbrt hat, bezeltgt Sd)ivarze im 2 rrchiv des Rriminalred)ts 1853 5. 273. "Innsbejondere gilt bies," fo fährt er fort, "bei ben Forit=

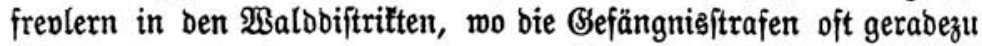
unvolftredbar und für bie frevler felbft nadjteilig fein würbent. 2lud) fragt fid wobl, ob nidjt bei ßerionen, bie ibr ßrot burdh Sanbarbeit verbienen, eine nod größere 2 usbegnung biejes Strafmittels angemeffen wäre, zumal wenn nan gebührende Rücffid)t barauj nebmen mollte, bem Sdulbigen von Zeit zu Zeit einige Tage Unterbrechung zur ßerjorgung feiner Îngehörigen, Die aukerbem leidjt ber Semeinbe zur Laft fallen, zu geftatten."

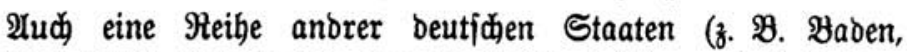
ßreukent) Gatten Strafarbeit obne Freibeitsentziehung, insbejondere bei froritübertretungen, in ben Sireis ihrer Strafmittel aufgentommen.

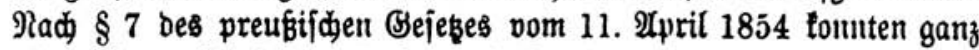
allgemein polizeilide \&sefängnisftrafen gegen Befangene, weldbe fid) auf ibre soften zu verpflegen auper ftande waren, audi it ber Beife volftreçt merben, baß bieje Befangenent währeno ber für bie Befängniştrafe beftimmten Beitbauer, obne in eine Befangen= anftalt eingeidloffen zu fein, zu Mrbeiten, welde ibren f̧äbig= łeiten unb פerbältuiffien angemeffen waren, angebalten murben.

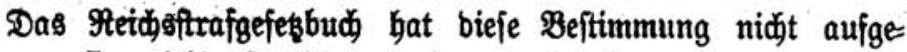
nommen, fie mithin für bie von ber $\Re$ teidsgeießggebung geregelten Delitte auggejololofien.

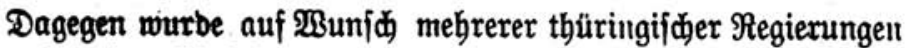

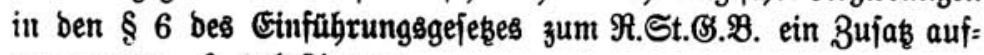
getrommen. $\$ 6$ beftimmt: 
"Pom 1. Jamuar 1871 ab barf nur auf bie im

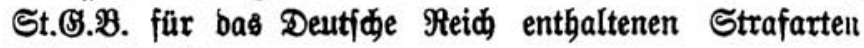
erfaunt werben.

Benn in Ranbesgefezen anftatt ber Befäng= nis= ober Belbftrafe Forit= ober Bemeinbearbeit angebrobt ober nadgelafien ift, jo bebält es hicr: bei fein Bewenben."

Die Faffung biefer Beftimumung iił eine wenig glütlidje. $3^{4}=$ näbit ideint ber $230 r t l a u t$ fid nur auf bie bereits beftehenden, nidyt auf bie łünftig zu erlafienben Rantbesgejeşe zu beżieben. Dod) baben 2 iffenjidaft und Bejekgebung fid, wie id glaube, aus guten

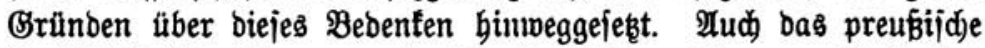
Forftbiebftablsgejes vom 15. 21pril 1878, weldes an Stelle bes ältern Geję̧es vom 2. Suni 1852 getreten ift, hat bie Forits unto Gemeindearbeit beibebalten.

Dagegen halte id es nicht für möglid, über ein anbres $\mathfrak{B e}=$

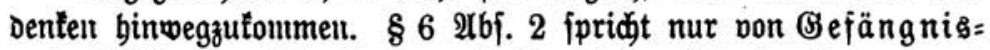
und Belbftrafe. Die Forft= und (semeinbearbeit barf bemnad) nidht an Stelle ber $\mathfrak{E} a f t$ treten. Daß́ jür biefe Bejdränfung

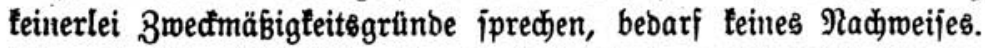

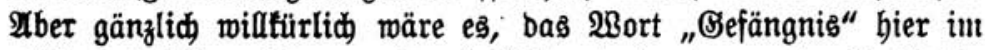
nidjt teduifden Sinme, als gleidbebeuteno etwa mit "Zreiheits= itrafe" ibberhaupt zu nebmen, wie Binbing (W̧anbb. I 304 Rote 24) uno DIshaujen (Ilote 7 zu $§ 6$ ) Dies wollen. Argeiebent von allen anvern Bebenten (joll "Befängnis" bier etwa aud Zưththaus uno Feitungshaft bebenten?) ift inshejonbere bie Thatiache ausf (laggebento,

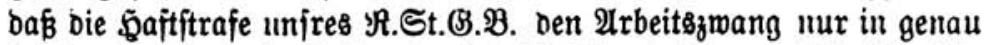

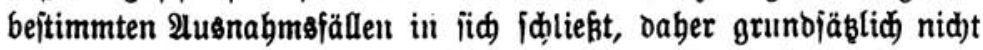

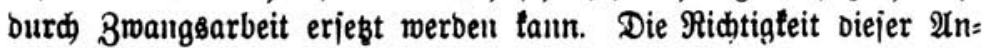
jidt wurbe bei ber Peratung bes preusifiden Feld= und Foritpolizei= geję̧es vom 1. 21pril 1880 alljeitig anertaunt. Der $\mathfrak{2}$ ntrag, an Stelle ber Saft Forft= ober Bemeitibearbeit treten zul Laffen, murbe

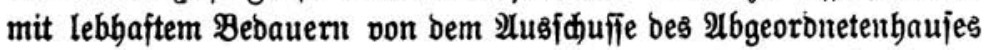

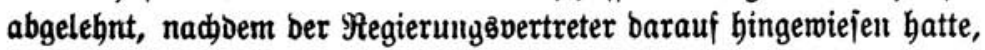

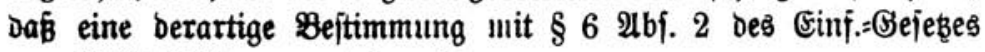
zum $\Re$.St.ङ.:. unvereinbar fei.

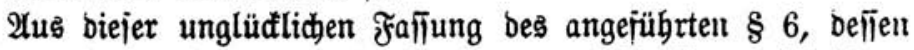

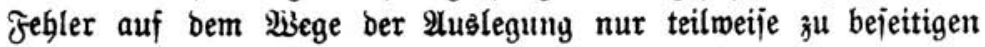

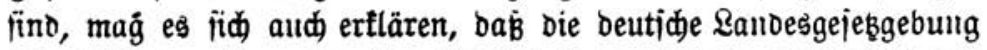

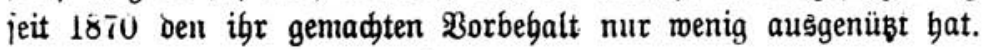




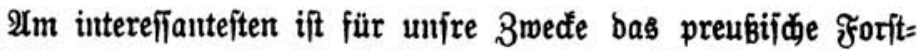
biebftablosgeies vom 15. 21pril 1878. Diejes verfiigt in § 14:

"Etatt ber in bem $\S 13$ vorgejehenen" (an Stelle ber

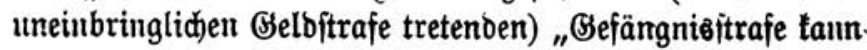
wäbrent der für biejelbe beftimmten Dauer ber ßerurteilte, audi) obne in einer Befangenaufftalt eingeidlofien zu werben,

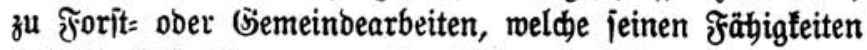
unto 2̧erbältniffen angemeīen fino, angebalten werben.

Die nähern Beftimumungen wegen Der zu leiffenben

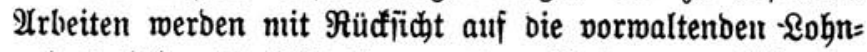

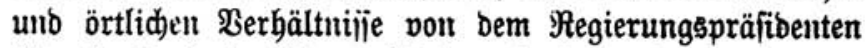
(Eaurobrojten) in Gemeinifaft mit bem Erften Staats= aumalt beim Dberlanbesgeridyte erlañen. Diejelben fino ermädttigt, gewifine Tagemerffe bergeitalt zu beitimmen, baß

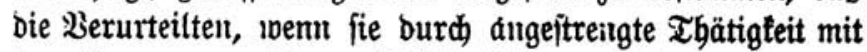
ber ibnen zugerwiejenen 2 rrbeit fruber zu ftande fommen, auld frither entlaffen merben."

Die Sdluß̧beitiminung biejes \$aragraphen gibt zu ntandjerlei

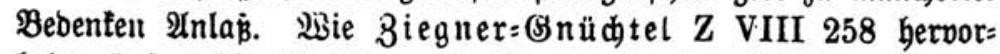
hebt, äušert bie Esinteilung in Tagemerfe eine \$3irtung uur zut

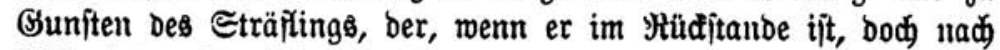

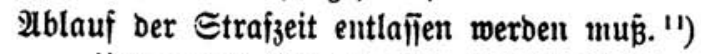

Unter nem Niamen ber prestations en nature ift bie

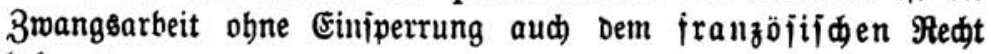
befannt.

Der Code forestier vom 18. 3umi 1859 beftimmt in 9 rt. 210 2bją 2 fif.:

"Liadministration forestière pourra admettre les délinfquants á se libérer des amendes, restitutions, reparations civiles et frais, au moyen de prestation en nature consistante en travaux d'entretien et d'amélioration dans les forêts ou sur les chemins vicinaux.

Le Conseil général fixe par commune, la valeur de la journée de prestatiou." ('Bgl. Rolland de Villargues Les Codes criminels II p. 208 ber 5. Iuff.)

11) Bebenten gegen Die Forft: unb (b)emeinbearbeit überbaupt bei iborg=

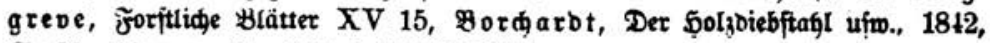

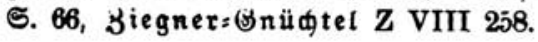




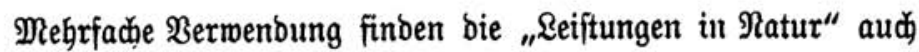

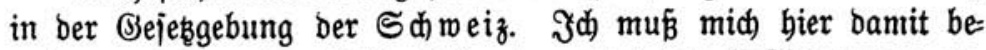
gnügen, einige mir zufälig betannt gemorbenen ßeftimmungen zu= fammenzuitellen. Eine volfiänbige Durdforidung bes jobmeizerifden

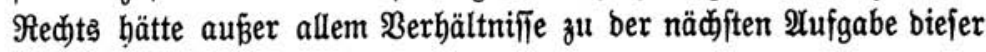
Beilen geitanden.

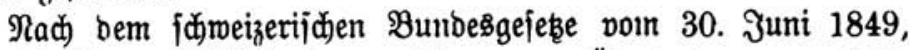
21rt. 28, fönnen Bselofitrafen, weldie megen übertretung von 3oll= und Steuergeję̧en ober Polizeiveroronungen bes Bundes erfaumt morben fitto, in Serfer ober in öffentlide 2rrbeiten obne Ein= fperrung umgemantelt merben.

Die Strafprozeboronung von ßern von 1854, 2 rt. 523, Debnt bieje Beftimmung auf alle 2 Irten von Belbítrafen ausి.

Der Canton du Vaud beftimmt in Irt. 7 bes (Sseję̧es vom 17. $\mathfrak{D}$ ใärz 1875 sur les établissements de détention:

${ }_{n} \mathrm{Si}$ l'amende est indépendante de toute autre peine, le condamné qui ne peut ou ne veut la payer en argent, peut se faire inscrire chez le receveur de l'Etat pour être employé à des travaux publics. Avis en est. donné au voyer du district ét à l'inspecteur forestier de l'arrondissement, qui peuvent requérer le condamné pour des ouvrages d'entretien et de construction de route, d'endiguement ou de sylviculture et l'admettre à acquitter son amende sous leur surveillance et leur contrôle, à raison de trois à six francs par journée, suivant la valeur de son tr'avail. A ce défaut, ou si le condamné n'exécute pas le travail qui lui est assigné, l'amende sur la déclaration de non-paiement délivrée par le receveur et en vertu d'ordonnance du travail du district, est transformée en emprisonnement, à raison d'une journée de détention pour trois francs d'amende."

Die 2 nmentoung biejer Beftimmung hat, wie Eorrevon auf Dem

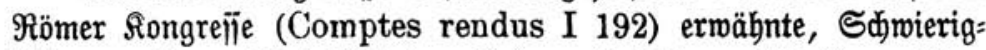

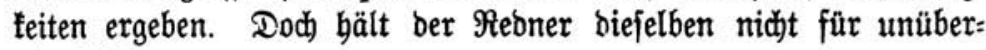
windlid.

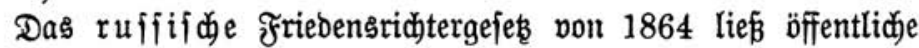
Irrbeit an Stelle ber einfachen ড̧aft zu. Die Bef́timmung fand aber feine praftijd)e $\mathfrak{A n m e n d u n g}$ und wurbe beshalb, wie Foin 
bein Rongreß zu Rom mitteilte (Comptes rendus I 188) in ben Entmurf bes St.S.\%. nidjt aufgenomment.

Das italienifhe St.ङ.P. von 1889 tennt biejes surrogato penale in einer boppelten Beftalt. Butädjit taun naç 2rrt. 22 2bf. 5 an ber Stelle ber uneinbringliden SSeldftrafe ftatt ber Einjidließsung auf Begebren bes ßerurteilten bie \&eiftung einer 2rrbeit (la prestazione di un' opera) für ben Staat, bie \$rovinz, bie Semeinde treten, wobei zwei $\mathfrak{A}$ rbeitstage gleid einem $\mathfrak{T a g}$ Fin=

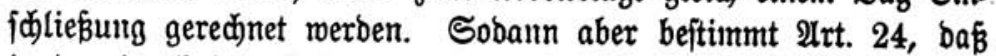

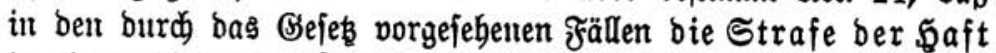

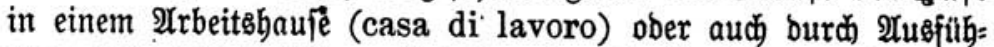
rung volt gemteinnüb̧igen 2 rrbeiten (mediante la esecuzione di opere di publica utilità) volfitrectt merben tann. Jm Beigerungs: falle tritt bie regelmäßige $\mathfrak{2}$ rt ber Strafperbüßung eitr.

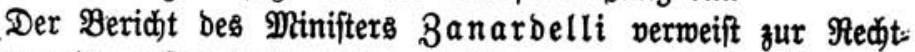
fertigung ber erftell biejer beiben Beftimnungen auf bie Thatjache, taßs fie in allen Entrürfen feit 1874 beibebalten worben jei (ein= gehendere Begrünoung in bem Perichte von Mancini). Er boitt,

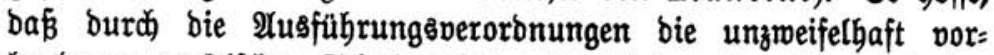
banbenelt prattifden Sđjwierigleiten bejeitigt werbett tönnen (relazione I 116). Bei ber zweiten ber beiben Peftinumungen batte ber Pinifter (relazione I 115) in utbereinjtimmung mit bem italienifden Juriftentag, welder zu Turin 1880 abgehalten wurbe (Berid)t:

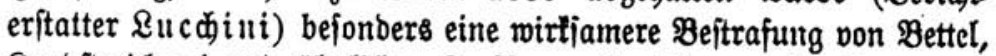
Sanbftreidjerei und äbnliçen jtrafbaren Sanblungen im 2 Auge.

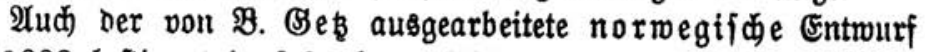
von 1888 beftimmt in $\S 32$ lekgter 9 Xbjaß̧, baß̧ bie an Stelle ber un= einbringlidelt Belbitrafe tretenbe Bsefängnisftrafe auf Begehren bes Berurteilten erjeşt merben Ianı burd 2 rbeit in Dienjte bes Staates ober ber Bemeinde. Reiber ipridyt fid bie Begrünoung bes

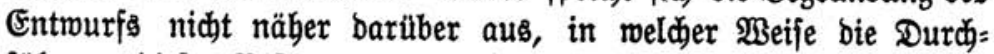
fübrung biejer Beftimmung gebach)t ift.

Ullo mun nod) einige Ritteraturangaben. IYrbeit ofne Ein= fperrung wurbe empfohlen poit

Bonneville de Marsangy II 293 (1864), Bulletin de

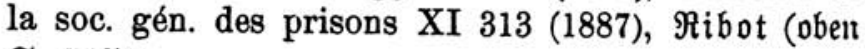
ธ. 750);

v. Solkenborff, arlg. beutjdje Strafrechtozeitung IV 654 (1864);

Beitífrift f. b. gef. Єtrafrechtsిm. IX. 


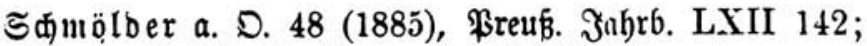
Ijळrott Z IX 46, \&ammajd Z IX 449;

Michaux, Bnlletin X 259 (1885), Labroquère, Bulletin XII 62 (1888); ferner von ber rheinij(d)=meftfälijđett G'efängutisgejelfjd)aft in ber Berjamntlung volt 1882.

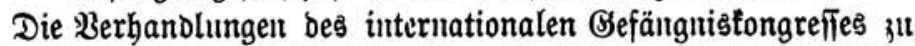
Rontoon 1872 habe id bereits oben S. 753 erröbut. $2 \mathfrak{H}$ f bem

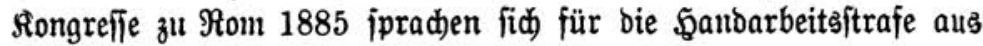
Teidjmann, be Nocito (bei Uneinbringlidjeit ber Belbftraje),

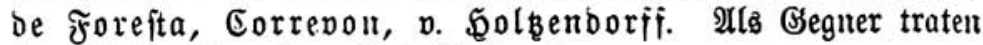
Sarofalo, Dreyfus, Foiniziti auf.

Yenerbings (Blätter für (Befängnisłunde XXIV 17) emprieblt v. Jageman" "öffentliche 2rrbeit, fei es mit Jnternierung zur

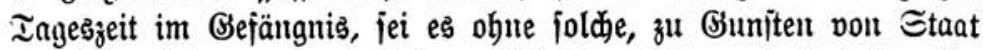

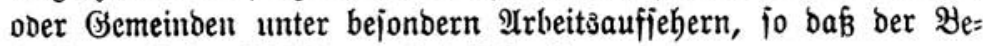
ftrajte nad) Der $\mathfrak{A r b e i t g z e i t ~ b e i m f e h r t . " ~}$

III. Der Berweis (B̉erwarmuty, avertissement, réprimande, admonition répressive, anmonizione, ripressione guidiziale) ijt vout ber (3ejekgebung veridicbenter 3eiten uno Länber vermertet morben. Won Den befauntert Bejtimunumgen bes römijö)en Rechts (3 D I 15 de offic. praes. vig.; 19 C. II 12 ex quibus caus. inf. irrog.) fomie von ber ßernendung bes $\mathfrak{B e r}=$

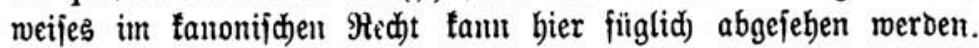

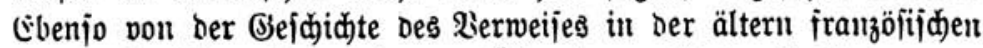

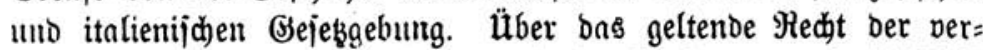
jdiedenten \&änder hat $\mathfrak{B}$. Alimena in ber Rivista penale XXVl.I 557 einte intereffante vergleidjente 2 lbhantung veröffentlid)t, auj weldee id) biermit bezüglid, ber Einzelnheiten Bezug nehme. $\mathfrak{A l} i=$ Itten a untericheidet in zutrefiender Wieife zmei Sruppen von Bejebs=

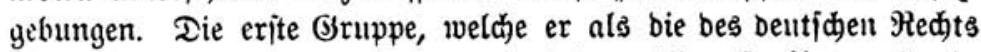
bezeidynet, feunt Den ßermeis nur bei gemifien ftrufbaren ţand:

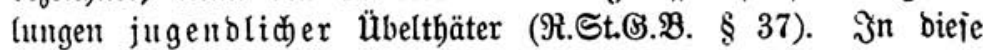

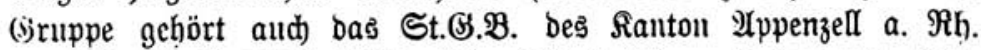

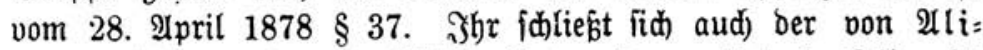
mena nidht ermähnte ruijijhe Entmurf ant. Und basjelbe gilt von Dent norwegijdien Entmuri voll 1888.

Tie jmeite (j)ruppe verwentoet den Sertueis, in bald mebr, balo meniger ausgebebutem Umjange, aud) gegen Ermadjelle.

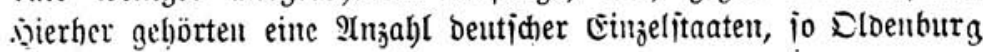




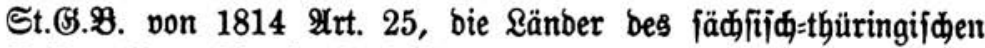
Redts, Braunidjweig St.G.P. von 1840 § 19, Wannover St.ङ.P.

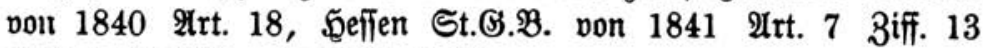
Baben St.(ङ.P. von 1845 § 49.

Jn bejonbers meitem Umfang (in nabezu 100 Fällen) madbt

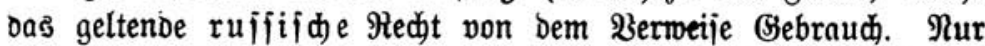
ausnabmsmeife vermentet ihn bas öfterreidijde St.G.P. von

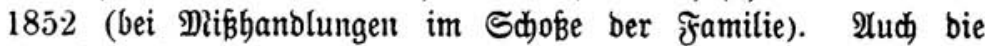
Strafgeję̧üd)er von Spanien uno ßortugal, bes Santons Ba abland und ber Jnjel Malta fennen ben geridtliden Berweis.

Dagegen ift er ben Strafgejesenen von Belgien, Solland, Ungarı uno andern Sänbern, fowie unter anbern ben öfter= reidijd)elt Entruürfen volt 1874 bis 1889 forwie bem ipanifden Entmurfe von 1885 fremb geblieben, aud mo es fid) um leidjtere Bergeben oder übertretungen jugendlider ßerjonen hantelt.

Uuf bie newejte italienijde Bejeßgebung, welde ben Ber= weis, bie riprensione guidiziale, mit ber Frriebensbürgidjaft in Berbintoung gebradt hat, fomme id) unten zu fpred)en.

Eine ausgebehntere $\mathfrak{A}$ menbung bes Permeijes ijt vielfach vorgeidlagen worben. Insbcjonbere von Bonneville be Mar: jangy 1864 in jeinem mehrermähnten Werfe utb vor turäem (1887) in Sd)oß̉e ber Société générale des prisons (Bulletin XI 314). Iod) hat (ïd) nad) eingebenden Berutungent bie erite Abteilung ber (Gejellid)ajt gegen Den Sorichlag ausgejprochen (Bulletin XII 150) unto, wie bcreits oben erwälyt, an Etelle bes Liermeijes bie 2lus= iebung oer Strajoollitrectung empiohlen (oben ङ. 757 ).

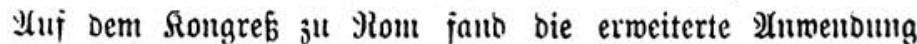
iitripreder in Teid)mann und Wocito. Dagegen murbe fie von (sarojalo, Dreyjus, Foinţ̨fi, J̧acquin leblyajt betämpit.

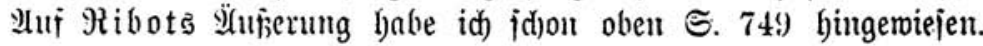

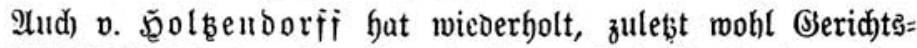
jaal XXXIX 34, Den Wermeis als Erjabumittel für bie furzzeitige

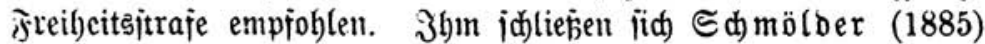

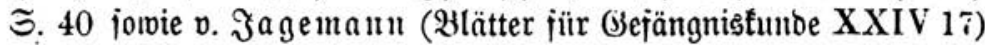

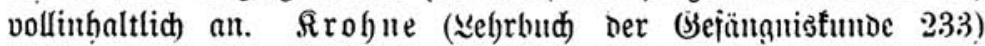

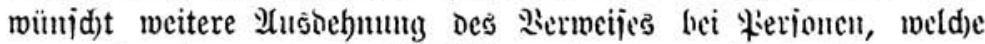
Das eritemal vor Den Etrajridster fonmen. \&lud) (jarraup,

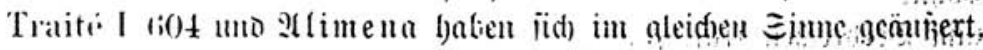




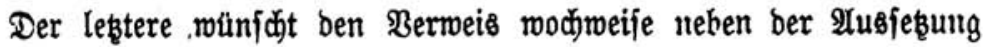
ber Strafpollftredung.

Dagegen bält Sontag Z II 499 ben Sermeis jelbft in bem

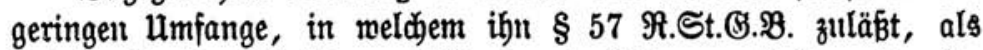
Sirininalftrafe nidjt für empfehlensmert. Wie man fieht, gehen bie

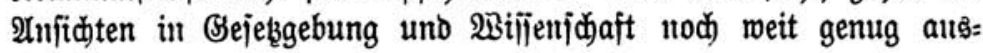
einanber.

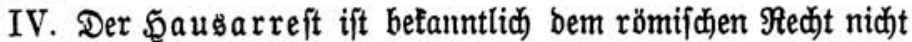
fremo gemejen. Die Stelle in 1. 9. XLVIII 22 D. de interd. et rel: Potest praeses quemdam damnare, ne domo sua procedat ift vielfach) angeführt unb vermertet morbent. Er finbet fich aber

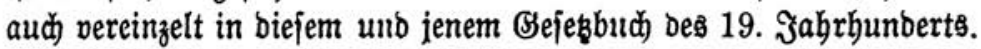
So in bem ber beiben Sizilien von 1819 als mandato in casa.

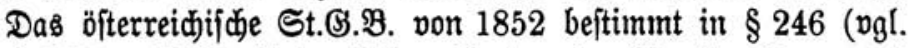

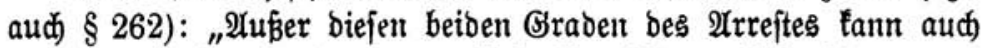
auf ફ̧ausarreft, entweber gegen bloß̉e 2 Angelobung, fich nidit zu ent= fernen, ober mit IYufftellung einer W3ache erfannt merben. Der Ђausarreft verpflidtet ben Berurteilten, fich unter feinem Bormanbe vom Қaule zul entfernen, bei Strafe, bie nod) übrige Irrrejtzeit in bem öffentlidjen ßerbaftorte zu volftrecten." \$raltijde Bebeutung hat, foviel iđj) meif, bieje Beftimmung niemals gebabt.

Das St.(S.2. von 3ürid), bas vielfach neben bem öiter=

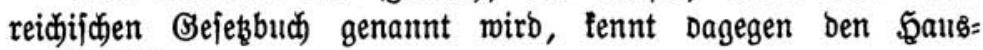
arreit nidyt.

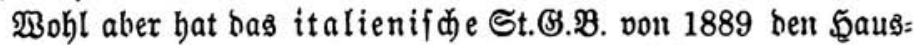

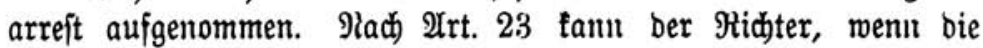
Straje ber \$ajt (arresto) einelt Monat nidjt überiteigt, unter $B_{e}$ -

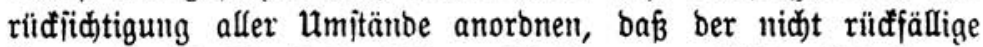
Wcrurteilte bie Strafe in feiner $\mathfrak{B}$ obuung verbüfe. Bei $\mathfrak{A r r e f t =}$ brud) ift bie ganze Strafe in ben gewöbnlidjen Saftlofalen zu ver= büben.

Die Begrünout des (şeję̧es hebt hervor (relazione I 105), Der Z3med ber Beftimmung bejtebe barin, foviel als möglid, obne ben Eharafter ber ভtrafe zu verwifdjen, Nadjteil und ভd)anbe ber Einfperrung bem Bürger zul erfparen, melcher geringfügige Befę̧es: übertretungen begangen hat, und $e \xi$ z̧ vermeiben, ba $\tilde{\beta}$ biejer an bas Leben uno bie traurige (Bejellidafa ber Befängnifife fich ge: wöhne unb fo jene Sdjen uno Sdjam verliere, welde ben Şang зum Berbrechen frạ̈tig zu zügeln vermögen. 


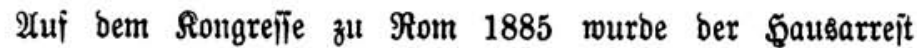
empioblen von Nocito, betämpft von Bsarajalo, Dreijus, Jacquin.

Für denjelben find neuerbings Эagemann in ben Olättern für (Gejängnistumbe a. D. und Srohne, Rehrbuch 233, eingetreten.

V. Die Friebenşbürgidaft ift in zwei burdaut verjobiebenten F̧ormen benfbar.

Die erite biejer Frormen tritt uns am anjđaullidjten entgegen

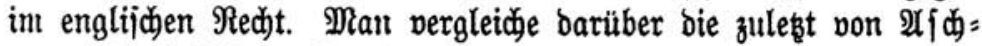
rott Strafeniyjtem ujw. in England S. 98 gegebene Daritellung. Jn biejer (Beitalt bezmectt bie Friebenabürgidjaft bie Sidjerung bes Friedents ber Bsejamtheit oder eines Einzelnen gegen Störung burđ̆ Begebung reçts̄mibriger W̧andlungen. Sie miro baher, grunbjäg̨lich wenigitens, neben ber zuerfannten Sseld= ober Freibeitsitrafe auf= erlegt. Dies ift aud) nody bie $\mathfrak{A}$ uffaffung ber englijiden Sonjoli=

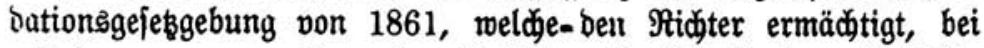
misdemeanours neben ober ftatt ber Freiheitsftrafe auf Eseld = ftrafe un Stellung einer Friedensburgidgaft zu erfennen (24 IItt 25 Vict. c. 96 bis 100).

So war bie Friebenşbürgidjaft aud im meientliden aufgejaßit

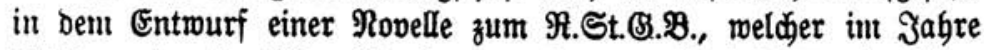

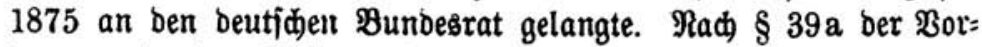

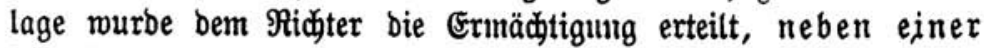
Freigeits: ober Bseloftrafe in ben burd bas Sejes vor: gejd)riebenen Fällen auf bie Reijtung einer Friebentobürgidaft im Betrage von 30 bis zu 3000 MR. unb für bie Zeitbauter von einent Dlonat bis zu einem Jahre zu ertennen. Die im Befeşe vor= gejebenen fälle betrafen: Bebrobung uno \&anbzrang, Đeraus:

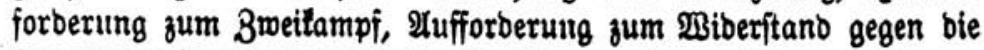
Staatżgemalt unb zu ftrafbaren ફ̧anblungen; ferner Rörperverlę̧ung, Sacjbejdäbigung, gewiffe Befährbungen bes öffentlicien Friebens (ङt.G.ß. §§ 130 uno 130a); enblic) ßerjuch einer ftrafbaren

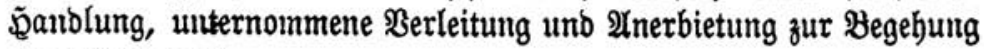
einer joldent. ${ }^{2}$ )

In biejer Geftalt meift uns bie Friebensöbürgịd)aft zurü auj die peinlidje Beridjtororonung Farls V.; in biejer Bejtalt hat fie fid) ill ben beutjijen \&andesirechten teilweije bis in bie neueite Zeit

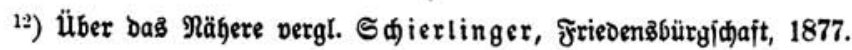


binein erbalten; in biejer Gejtalt ijt fie aud ber auperbeutiden Sejeßggebung unjres Jabrhunderts nidjt fremo geblieben. ${ }^{13}$

Meiner Meinung nad fann es auch gar teinem Bmeifel unter=

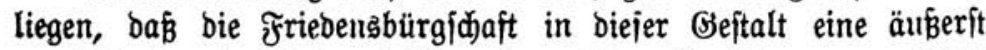

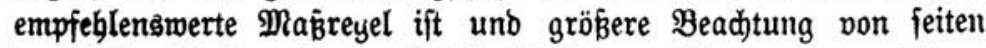
Der Wiffenridaft verbient, als ibr bisher zu teil gemorden. \$enn fie, insbejondere pon beutidjen Edriftitellern, wegen ber ",Ber= mengung polizeilicher und rechtlider Befichtspuntte" befämpit worben ift, fo bürfte bicier Bormurf bem 2Injeben ber ihn erbebenden Sdariftiteller gefäbrlidjer fein, als ber von ihnen betämtpften Ein: riditung. ${ }^{1+}$ )

2ber an biejer Stelle interejiitert mid bie Friebensbürgiddaft in biejer igrer eriten Seftalt nidjt. Sier mödte id vielmebr barauf - hinmeifelt, baß fie geeignet ift, an bie હtelle ber furzzeitigen Freibeitsftrafe zu treten, ober genauer geiprochen, andern Erfak̨unitteln ber turzzeitigen Freibeitsjtrafe bell nötigen Radorud zu verleigen.

In ber Sitteratur hat, foviel id fehen fanm, bejonders $\mathfrak{A} j$ d) rot t biefe zmeite uno, wie id glaube, weitaus widttigere 2ufgabe ber

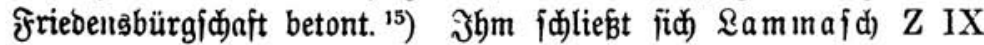
448 an.

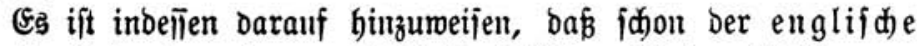

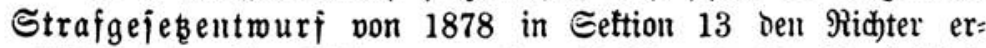

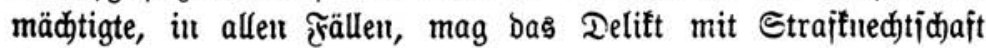
ober mit Gefüngnis ober mit Gielojtraje beoroht fein, neben ober

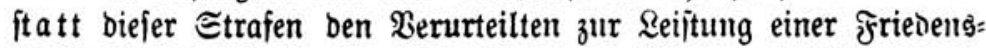
bürgid)aft in einem vom (Beridte zu heftimmenden Betrage an: zubalten. Dieje Bejtimmung geht mitbin über bie oben erräbnte Borjd)rift Der Sonjolioationsyejeße weit hinaus; iie ijt jenod) nid)t geltendes Redjt gemorden und ber Serjajier bes Entmuris, James Finjames Stephen, fodeint ihr feine bejondere Bedeutung beigelegt zil baben. ${ }^{16}$ )

13) Wiun vergl. Die (Beję̧gebungen von Saðcn, Trrantreiđ), Dänemart, Gpanien. (Senaueres Eingehen auf Diciclben liegt nidt in meiner 2 (bfid)t.

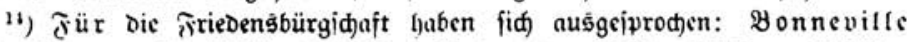

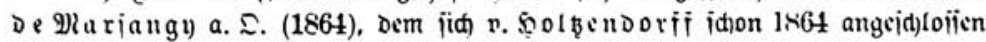

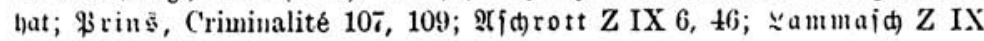

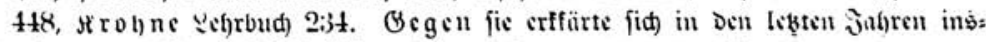
bifondere v. SHuri Z IV 171 aus Dem oben angedenten Brumbe.

1.) Etrufeniujtem und Bejüngnisncien in Ënglans, Є. 101 und Z IX 46.

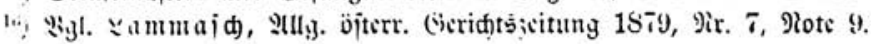




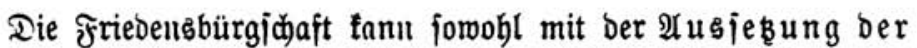
Strafoollitredung als aud mit bem riduterliden :ermeis verbunden merben. Die lektgenannte Berbindung finden wir in

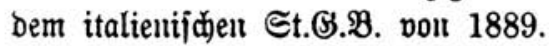

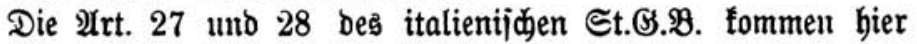
in Betradidt.

Danad) fann an Stelle ber Einidjließ̧ung und bes Arrejtes (detenzione und arresto), menn beibe Strafen bie Dauter eines Ponats nidjt überjteigen, an Stelle ferner ber Beritriđung (confino) unb oer örtlichen ßerbanmung (esilio locale) von nidjt über brei Monaten, an Stelle entlich ber breihunbert \&ire nidjt überiteigendent Geloftrafe, wenn ber Berurteilte in Den leżten fünf Jabren nidht bejtraft morben ijt, ber ridjterlidje $\mathfrak{B e r m e i s}$ (riprensione guidiziale) treten. Bugleich hat fich ber ßerurteilte allein ober mit einent ober mebreren Bürgen zur 3ahlung einer beftimmtelt

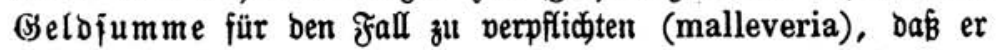
innerbalb eitres bejtimmten Beitraumes neueroings eine fitrafbare Waullung begehen jollte.

Der Beridt bes Minifters (relazione I 119) rediffertigt in

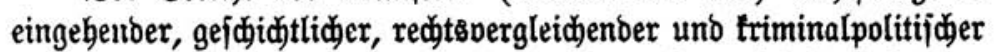
Begrünourg bie \&ufnahme biefer \$ejtimmung, für melde insbejonoere \&uçjini mieberbolt uno mit gröster Entidiebenbeit eingetreten ift.

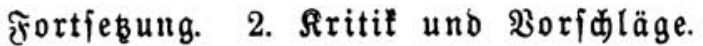

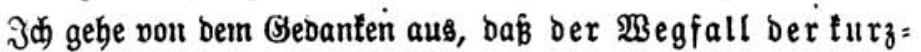
zeitigen Freibeiteftrafe, b. h. ber Eillperrung bis zu jeds \$od)en münidenswert uno möglid. iff. Das würoe

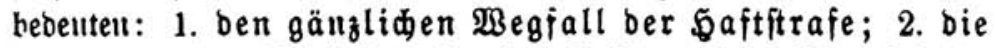

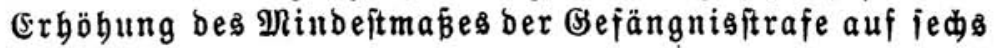
$2 B$ od)ent. Die Frage ber Fejtungshaft fann bier nod) unerörtert bleibert.

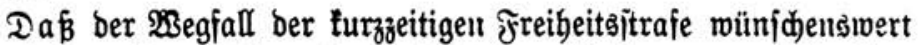

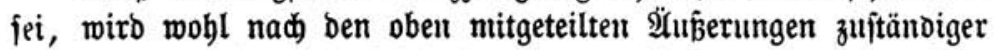

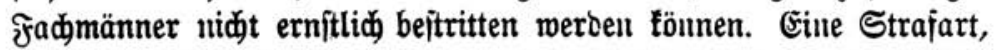

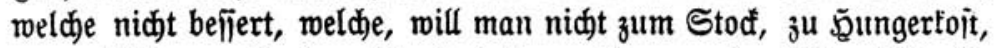

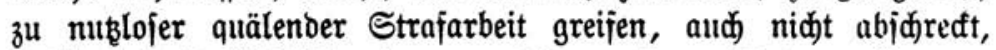

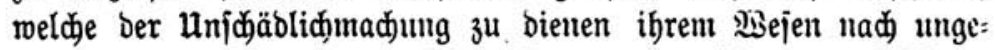
eignet ift; eime Strajart, roeldje nidts nüktt, wohl aber viel ja)adet 
und überoies toftipielig in jeber Peziehung ift: eine joldje Strajart hat teine Dajeinsberectigung ${ }^{17}$ ).

über bas Minbeftmaß̧ ber tünftigen Freiheiț̄itrafe mag man

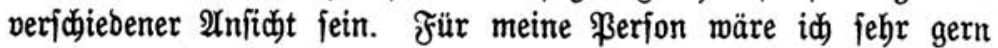
geneigt, nod) höber zu greifen. Aber es handelt fich barum, ßor=

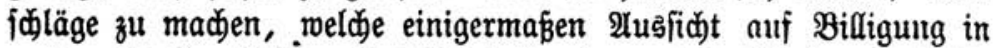

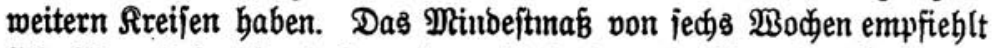

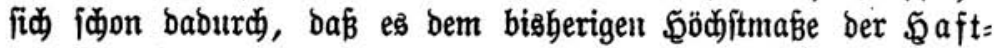
ftrafe entipridt, ben ßegfall biejer Strafart ermöglident und bamit bas Syjtem ber Freiheitêtrafen mejentlid vereinfadjen müroe. Wie

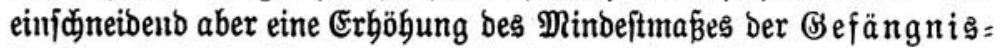

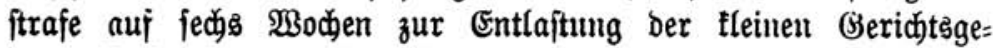

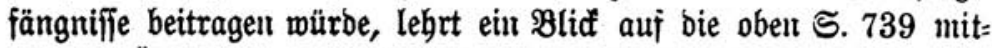
geteilte überfid)t. Die \&öjung ber Befäınnisjage, heute nod) megen ber Bautoiten in weitefte Ferne gerüdt, exjめeint in bern 2ugenblicfe als burdffülyrbar, in weldeun bie furzzeitige freiheits= ftrafe fällt.

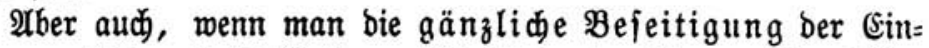
iperrung bis zu feçs Woden nidjt für notwendig eradjten jollte, wirb bie möglidjfte Einjめ)ränfung berjelben verlangt werben müfTen. 2(uch für biejen Fall tönnen bemmach bie folgentoent $\mathfrak{A} u \xi=$ fübrungen auf Beadtung Inifprud maden.

In welder $\mathbb{B}_{e i f e}$ ift ber Eriaz̧ ber furzzeitigen Frei= heitsftrafe möglid? was tann und joll an ihre Stelle treten?.

Das Material zur Beantmortuing biejer Frage habe idy in bell

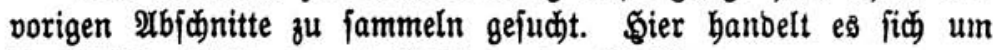
bie tritijhe Siditung unt Prufung bes Stof̈ęs.

Dabei tanu bie Prügelftrafe aus bem Spiele bleiben. So= weit fie jugenblidgen Berbrechern gegenüber empfohlen wordent ift, tomme id allf fie in einem anbern 3ujammenbange zurüd. 2Uls Disziplinarftrafe gegen ermadjene Uumberbejierlide hat bie \$rügel= ftrafe nit ber Erörterung ber gegenmärtigen Frage nidjts zu thun. Unto ganz abgejeben von allebem fdeint es mir in jeber Beziebung

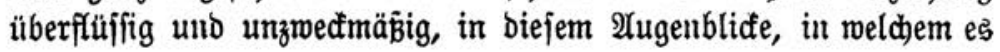

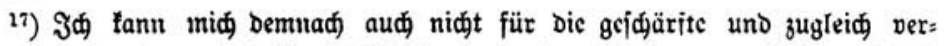

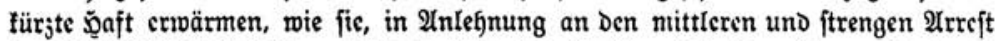

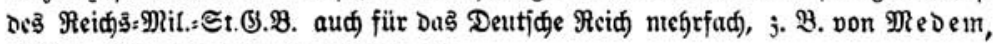
Z VII 15s, vorgejdlagen morden ifft. 
(iid) um bie Gewinning ber eriten (Brunblage für friminalpolitif de Rejormbejtrebungen hanbelt, burd bie Sereinziebung biejer bie

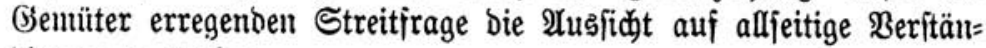
bigumg zu trübelt.

2Uud will id̆ hier nicht weiter barauf eingebell, baß̄ burd) eine Umgeitaltung ber Soldoftrafe und ihrer Eintreibung eine rejentlid, crweiterte 2 Inwendung berjelben und bamit eine bebeutfame Ein: ¡d)räntung bes Ģebietes Der furzzzeitigen Freiheiteftrafe ermögliddt weroen würoe.

Aber eill allores muß und will id betonten. Es hanbelt iid) nidjt um eine $\mathfrak{R i l b e r u n g}$ unfres Strafenfyftems.

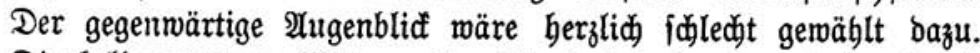
Die beflagens?werte Dilbe unfrer Strafgejęgebung wiro nur burd Die nod beflagenşwertere Milde unfrer Strafgeridjte übertroffen.

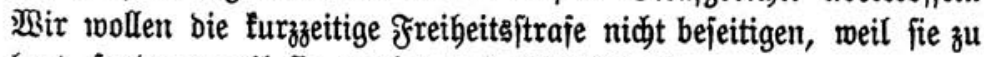

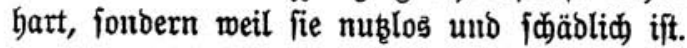

Es handelt fid ferner aud nidgt um eine Erweiterung bes ridterliden Ermefifens. Die Strafrabmen unjrer Befés: bücher find wahrlid mebr als meit genug, und bie "riduterlide

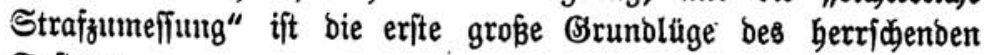
Snftems.

Bon biejem Bejidjtspuntte aus ntuß id mid mit aller Ent= idjebenheit gegen bie erweiterte 2 nnwenoung bes einfachen rideterliden Berweifes, alfo des Berweijes obue 2uffegung

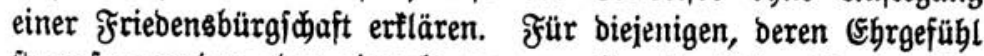
ftuntpf gerworben ober niemals rege gewejen ift, ift ber ßerweis bes Riduters eine Romöbie ogne jebe errifte Bebeutung; futr ben Ebr= liebenbent ift er eine tiefe \$erleģung, eine fibwere Rräntung. F̧ür beibe bleibt bas "Sduutbig im Rament bes Bejeses"s", bie "Berur=

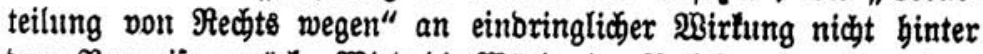

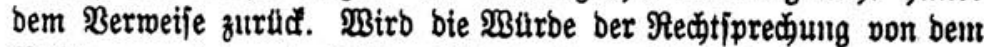

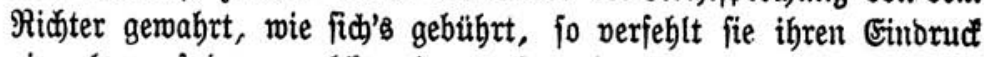
niemals auf ben, welder bas erf́tental vor ben Sdranten bes Geridftes erfaneint. Sener unnabbare Errift bes Utteilsjpruches

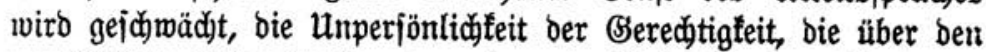
menijhliden Reibenidaftent in unberwegter $\Re$ ube thront, wiro herab=

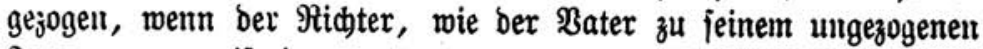
Jungen, verweifent unto verwarnend zu bem Berurteilten fpridht,

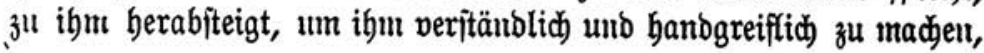




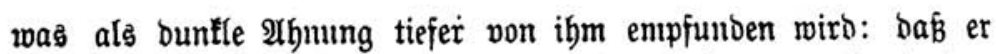
bie Rechtsoromung gebrodhen hat uno ohnmäd)tig munmebr in ber Semalt ber Rechtsoronung fic) berinbet.

Diejelben Bebenten ipredjen, wie idj glaube, audj gegen Den,

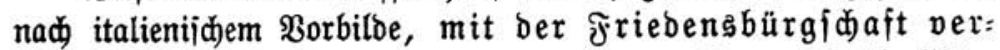
bunbenen 2erweis. Es tritt die Ermägung hinzu, baß̧ bie Miög=

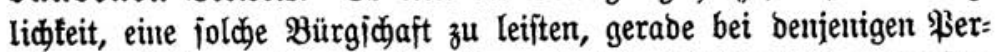

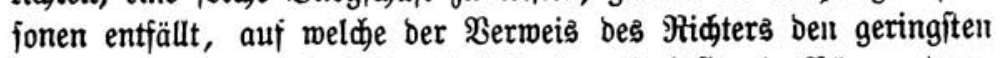

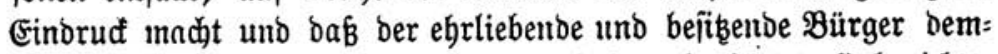
nach Doppelt jo jadwer getroffen wirb, wie ber abgehärtete Қabenidhts. Der Berweis erjdyeint baber, jomeit es fid um Erwadjiene handelt, in jeber feiner beiben Sejtalten, als ungeeignet, bie furzzeitige Freiheitsjtrafe zu eriezen. $\mathfrak{A n}$ biejem Ergebnifje wiro nidjts ge= änbert, menn man aud̆ in eirzelnen $\mathfrak{A}$ usnabmsfällen ben Berweis wahlmeife neben Freibeitştrafe von furzer Dauer anbroken wollte. Die $\mathfrak{A}$ ufgabe, bie wir uns geitellt, heijht burdgreijente Mit halben Makregeln ift niemandem geoient.

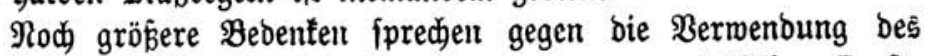

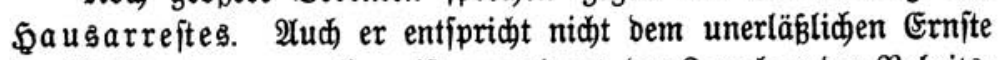

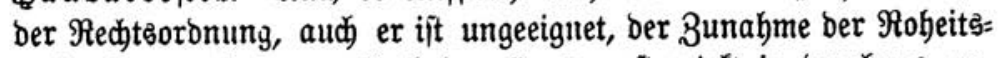
verbrecben zu fteuern. 2lud ber Sausarreft mirft it burdjaus un= gleidjer Єळmere auj bie veridiebenen Rlaj̄en ber Berurteilten; fdower trifitt er alle, meldje igren Rebelisunterbalt außer ber eignen \$obnung zu judjen verpflidjtet finb; leidjt erträgt ihn, wer im Bimmer arbeitet ober in feinem. Rabell bie Sumben bexient; unall= rentobar ift er gegenüber bem (j)ejindoe, das barauf angemiejen iit, bie Befehle ber Serridiaft auڤzưüüren.

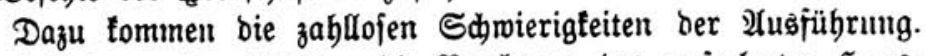
ßie joll in grobelt Stäbten bie Beadtung bes aujerlegten நaus:= arreftes überwact, merben? \$ill man etra jebem Serurteilten einen Sdjubmann an bie Seite ftellen? Die Rojten ber Strafrechts= pflege mürben fid) auf bieje $\mathfrak{A}$ rt faum vermindern. Unjern Straf:

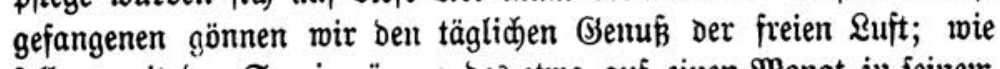
foll es mit ben Spaziergängen bes etwa auf eitren Donat in feimem Sauje veritrictten Arreitanten gehalten werben?

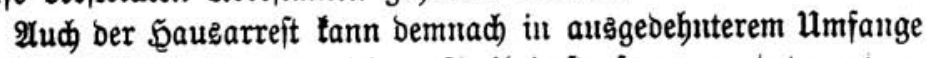
nidyt zum Erjaz ber furzzeitigen Freiheitsftrafe verwendet merden.

Daşfelbe gilt aber aud von bell übrigen, öjter vorgejd)lagenten, in bem vorbergebenden $\mathfrak{A b j}$ butte von mir gar nidbt bejonders $\mathrm{cr}=$ 
wäbnten Bejđränfungen ber perfönliden Freibeit. vol: Jagemann a. D. 17 ermähnt bie folgenden:

"Wirtshausverbot, Drtsperbot, Eingrenzung (Der Ronfinierte barf ohne Erlaubnis ber Dbrigfeit wäbrend ber Strafoauer betr Drt nid)t verlaffen), Berbot bes \$affentragents ober $\mathfrak{B a f f e n b e f i z e s , ~}$

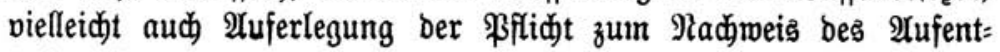
balts.." ${ }^{18}$ )

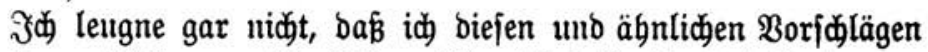

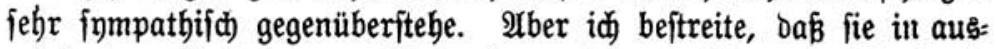
gebehnterm $\mathfrak{u m f a n g e ~ z u r ~} \mathfrak{A n m e n o u n g}$ tommen tönnen. Wie benft man jidf z. $\mathfrak{B}$. Die Durdfführung bes. $\mathfrak{B r t 5 h a u s v e r b o t e s ~ i n ~} \mathfrak{B}$ erlin ober Mündjen? Wollen wir Stimmung madjen für bie \$ejeitigung ber furzzeitigen Freibeitşftrafe, fo mü|̄̄en wir zunädjit wenigittens abjeben von Borjalägen, beren ßermirflidung nur unter łlein=

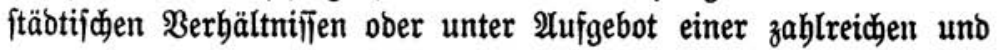
gut geidulten \$olizemadot möglid ift.

Ģanz anders verbält es fich mit ber Strafarbeit obne Ein=

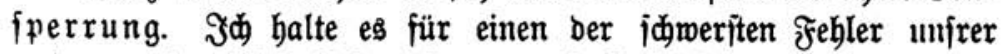

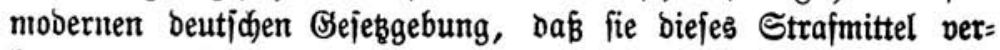
fümmern ließs. Die Einfperrung ift esi, meldje, mieberbolt für fürzere Zeit angementoet, entïttlidjend mirtt; bie Zmanģarbeit ohne Einjperrung ijt von biejem Mangel frei. Der Maun, ber Tags über gearbeitet hat, fehrt abentos in ben Sdjok feituer Familie zurüđ. Daß ber Ertrag feiner Reiftungen nidht ihm, fondern bem Gemeinmejen beimfält, bildet ben einzigen unterid̄ieb berjelben von ber freien $\mathfrak{A}$ rbeit. Diefer Unteridied wiro ign alleroings empinind= lid) Drüden: aber bie Straje foll ja als ein übel von ibm em= pjuntell merben.

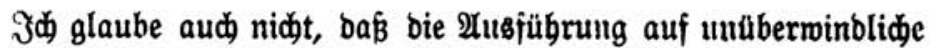

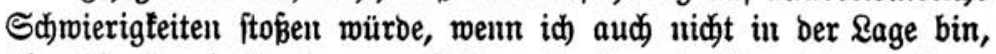
über bie Ergebnifie ber preupijdjen Forit= uno Semeinbearbeit an biejer Stelle Z3uverläjifiges zu beridhten. Wiro bie Zmantgararbeit,

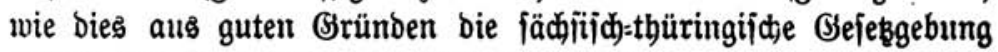
gethan hat, bejobräntt auf biejenigen ßerjonen, meldhe burd Wand= arbeit ihren Unterbalt verbienen, fo wiro es nidyt fower fallen, geeignete $\mathfrak{A}$ rbeit zu finden. 2 uf belt Ertrag berjelben tanr ber Etaat um jo eber zu Gunften ber Bemeinden verzidtell, als er nidjt

18) Bgl. aud Rrohne Segrbuc S. $23 \pm$ Rote 3. 
unbeträchtlicje Eriparungen in feinen $\mathfrak{A} u$ gagaben für bie Gerichts: gefängnifje madben wiro. Den (S)emeinoen aber wiro es niemals

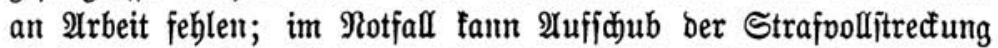
eintreten; bie Bermijđung mit freien $\mathfrak{A} r b e i t e n$ ift burdaus unbe: Denflid); bie überwadung madbt feine Sd)mierigfeiten, menn bie Urbeit uidat nach ber Zeit, jonbern nad) ber Reijtung bemeffen miro.

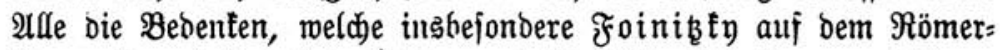
Songreffe geäubert hat, fiheinent mir binfällig, fobald man nicht an Die Erbaum! bejonderer \$rtbeitşanjitalten (atéliers pénitentiaires) oder gar an bie Erridatung von $\mathfrak{A}$ rbeitertolonieen benft.

Trob̧ alledem halte id bie Strafarbeit nidat für geeigntet, an bie Stelle ber furzzeitigen Freibeitsjtrafe zu treten. Wenigitens un= mittelbar nidjt. Sie ift vielmebr nadj meiner Dieinung bas ge= eignetite Erjaģmittel für bie uneinbringlide Belditrafe, jo Duß fie bie furzzeitige Freiheitsftrafe nur, fomeit bieje ftatt Der

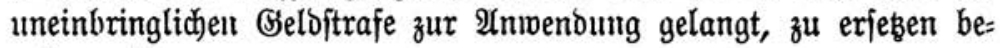
rufen märe.

$\mathfrak{A n}$ und für fid) ift bie unentgeltliche $\mathfrak{A}$ rbeitsleijtung, jei es an Den Staat, fei es an bie Semeinde, ber ßermögenşftrafe näher verwandt, als ber Freiheitştrafe. Es tritt bie weitere Erwägung hinzu, baß bie Strafarbeit gegen biejenigen, weldje nicht von ihrer Sänbe $\mathfrak{A r b e i t}$ leben, überhaupt nidjt angementet werben tönnte, ohne

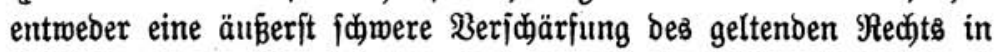

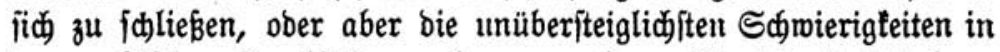
Der praftijiłen Durdführung berworzurufen. Die Strafarbeit fann uur als Tagelobnarbeit allgemeinere Inmenoung finben. Der Staat tann nidht ben Sdupter ober Sdueiber anbalten, ihm Stiefel

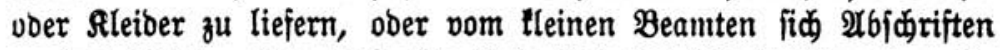
maden lafien, obne baß̧ ibn bieje 2 rt bes Strafoolzuges mehr toftet als bie juöniten Strafanitalten. 2Uber Steine flopfen, Wege ausbefiern, Mauern aufiuthren, ફ̧olz vertleinern Iafien - das ift

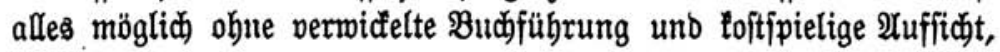
ohne \$ergettoung von Z3eit uno Sraft Durd) bie Behörben.

In Der Beidränfung auf Tngelohnarbeit aber mürbe bie :3mangs=

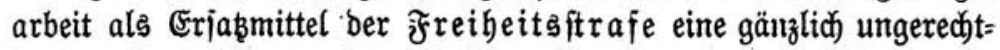
fertigte Begünftigung einer eiızelnen Bevölferungstlafje billoen. Der

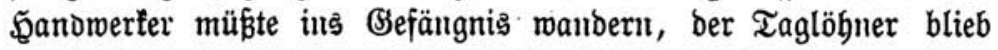
gerabe jo frei, wie er es inmer ift. Das bebari feiner meitern

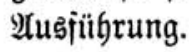


Bantz anders liegt bie Sache, went wir bie Strafarbeit als

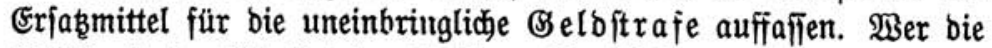
Beldftrafe bezablt, hat bamit feiner Berpflicftung genügt; wer fie nidyt bezablen famn, ber leifte bem Staat feine Urbbeit. WSirb bas: "Iidut=bezablen = fönnen" ernit genommen, fo bürfte ber Fall wohl ausgejdlofien fein, Daß bei andern ßerionen als bei \$altbarbeitern bie Bselbftrafe als uneinbringlid) erjobeint.

Rur eine Frage bebarf nodj einer furzen Ermägung. Wie

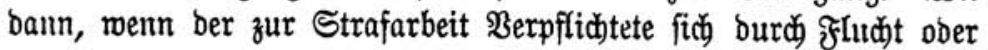
Beigerung ber Reiftung feiner Berpflidutung entzieht? F̧ür biejen Fall bleibe man bei dem bisherigen Srunbjake und laffe bie Frei= heitsftrafe, b. h. bie Einfperrung an bie Stelle ber uneinbring= liden Beldftrafe treten. Alber woblgemerft: Freibeitsftrafe nidht unter fects $\mathfrak{B o d e n . ~ D e n n ~ e i n e ~ a n b r e ~ F r e i b e i t s f t r a f e ~ g i b t ~ e s ~}$

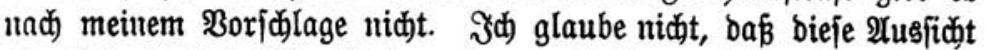
cine befonbers fräftige Sodung bazu enthalten mürbe, einer Straf: arbeit von wertigen Tagen aus bem $\mathfrak{B e g e}$ zut gebent.

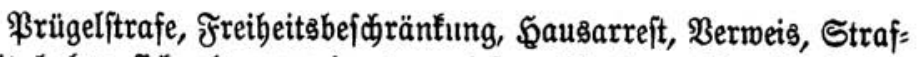
arbeit haben fid als ungeeignet ermiejen, bie turzzeitige Freibeitos=

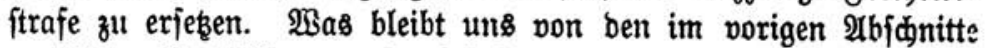
erwähnten Borjølägen nođ übrig?

Mit aller Beftimmtheit trete id für bie Einführung ber Uusfeßzung ber Strafpollftredung, fei es mit, fei es obne Friebensbürgfdaft, in unjre Sejęgebung ein.

Die Borzüge biefer Einridtung ergeben fich aus bem bisher (Bejagtell. Es handelt fich mur um ibre prattifide Durdjführung.

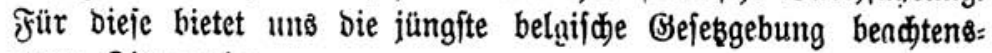
werte Fingerzeige.

Bergegenmärtigen mir un bie praftifdje Tragmeite eines $\mathbb{B e}$ jeł̧es, weldes bie "bebingte Berurteilung" im Sinme bes belgifd)en Rechtes einführte, im Zufammenthange mit ber von mir vorge= fatlagenen (Erböbung bes Mtindeftmakes ber Freiheitsftrafe auf fechs Modien.

Der IIngeflagte wirb verurteilt. Wirb bas Urteil vollftrectit,

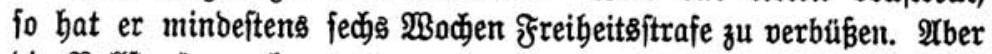
bie $\mathfrak{B}$ olfitrectung fann auggejeşt werben, wenn es fid um einen Ingeflagten hanbelt, welder zum erftenmal eine Berurteilung zu

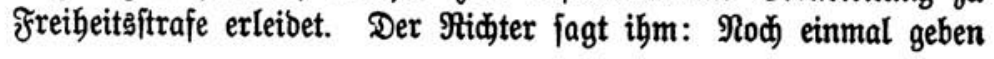


wir bein Shidjal in beine Santo. Wenn bu innerhalb ber bir be= ftimmten Frift nid)t abermals eine mit Freibeitsftrafe bebrobte \anblung begebjt, bleibt bie Strafe bir erlafien. Int antoern Falle

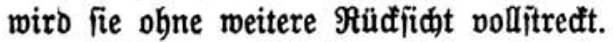

(sinigt man fid über biejen Brunbgebanfen, fo mirb es nidit

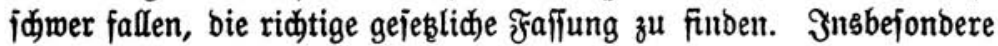
wiro es leidt fein, bie frriebensbürgidaft mit ber Âsjekzung ber Strafpolftredung in Serbindung zu bringen.

An biejer Stelle bin id. nodh nidft in ber Rage, meinerjeits

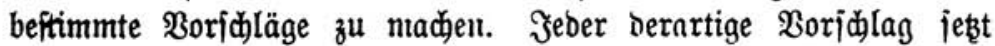
eine vorangebento Beritänoigung ïber bas Strafeninjtem voraus.

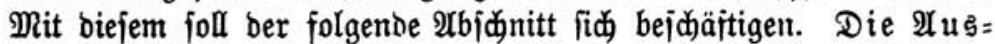
iezung ber Strafpollftredung aber ijt bie erite friminal= politifde Frage, welde, unb zmar in nädjter Zufunft, wijienjdaftlide söfung finbell wirb. Das iit meine fefte, auf Thatiadjen geftübzte überzeugung. Damit ij̄t aber bas \$roblem einer geeigneten Bebandung ber Selegenheits= verbreder zum weitaus größten Teile gelöjt.

(䒠orticķung folgt.) 